\title{
Modelling and Optimizing Operating Conditions of Heat Exchanger with Finned Elliptical Tubes
}

\author{
Stanisław Łopata and Paweł Ocłoń \\ Cracow University of Technology, Cracow \\ Poland
}

\section{Introduction}

High performance heat exchangers are widely used in many industries such as petrochemical industry, automotive industry, energetic industry and many others. The name of this kind of heat exchangers is in consistency with their structure. Large heat transfer area leads to high thermal efficiency of the device. Its working principle is to cool rapidly large amount of gaseous or liquid medium. Because of its compact size, it is possible to use it for easy installation in various systems, like the heating, drying, air conditioning and the other systems.

High thermal performance of this type of heat exchangers (Nagatha, 2004; Ibrahim \& Gomaa, 2009) is achieved due to large packed rectangular fins on tube surface, as well as the shape of the tubes. The elliptical shape ensures better distribution of velocity along the tube circumference during the flow, as well as lower pressure drop in comparison to the circular shape (Matos et al, 2004; Jang \& Yang, 1998; Li et al, 2006; Nishiyama et al, 1988; Khan et al, 2004; Saboya \& Saboya, 1981; Saboya \& Sparrow, 1974; Bordallo \& Saboya, 1999). Consequently, the coefficient of heat transfer in the elliptical shape is larger when compared to the circular shape (Idem et al, 1990; Rocha et al, 1997; Taler, 2009). It brings about that the heat exchange process is more efficient in elliptical than in circular tubes.

To use all the aforementioned advantages, it is necessary to ensure uniform distribution of velocity in all the tubes. Failing that, it leads to large differences in mean temperature in the tubes. Consequently, excessive thermal stress occurs, that may cause the heat exchanger to break down. Small volume of collectors of the heat exchangers implicates possibility of improper flow condition inside the tubes, causing unsuitable inner distribution of thermal and mechanical loads. Damages to a tube, Fig. 1, as well as a tube bundle prone to buckling, Fig. 2, prove, that such a failure is possible (Łopata \& Ocłon, 2010; Ocłon \& Łopata, 2011).

Compressible stresses are undesirable (Łopata \& Ocłon, 2010; Łopata \& Ocłon, 2011) in this type of construction, because the allowable compressible load (allowable buckling stress) for a slender tube is significantly lower than the safe tensile load.

The simplified method to assess failure of a high performance heat exchanger with finned elliptical tubes is presented in the paper. The diagram, shown on Fig. 3, presents the method. The geometrical representation of construction - a CAD model is prepared at first. Next, on the basis of prepared geometry, numerical representation of the model is created. Afterwards, the flow computation - CFD (Ferziger \& Peric 1999; Anderson, 1995; Gresho \& 
Sani, 2000; Chung, 2010) is carried out using the commercial tool ANSYS CFX (ANSYS, 2008). It is desirable to obtain the uniform mass flow rates in all the tubes of the heat exchanger, because it ensures the appropriate heat transfer conditions for the device. When the mean velocities in tubes differ significantly (Łopata \& Ocłon, 2010), new modified collectors are applied to improve flow distribution inside the device (Ocłon \& Łopata, 2011). If the liquid distribution among all the tubes ensures safe heat transfer conditions, the CFD computation is stopped. The results obtained with the CFD analysis as the bulk temperatures $T_{\text {bulk }}$ and the heat transfer coefficients $h$ are transferred next to a code, that calculates temperature distribution inside the elliptical tube, using the Control Volume Method (Chung, 2010; Taler \& Duda, 2006) as the mixed type boundary conditions (Incopera, 2001). The obtained temperature and pressure values are used as thermal loads for structural analysis, using the ANSYS Structural (ANSYS ADPL, 2009) software.

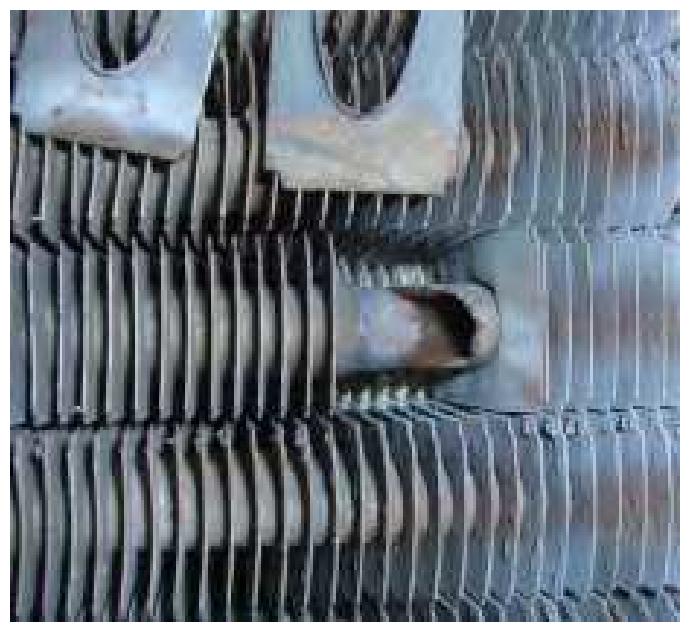

Fig. 1. View of damaged tube

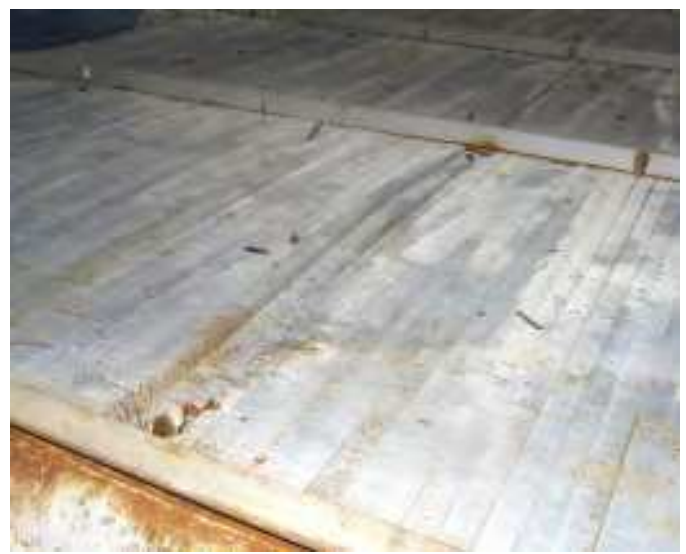

Fig. 2. Buckled tubes of a high performance heat exchanger 


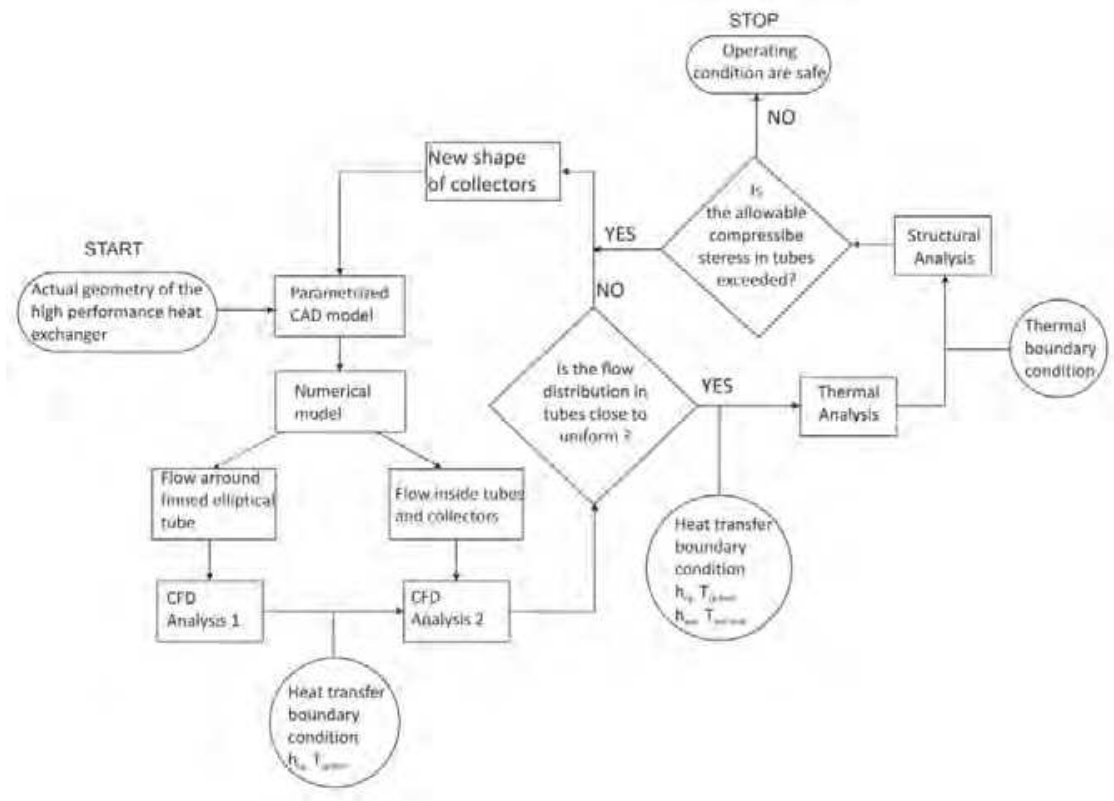

Fig. 3. Calculation methodology

This commercial tool computes displacement and stresses for the numerical model of the heat exchanger using the Finite Element Method (Reddy, 1993; Logan, 2011; Smith \& Griffiths, 2004; Zienkiewicz \& Taylor, 2000; Hutton, 2003). Structural analysis allows finding the zones and locations where allowable stresses are exceeded. When it happens, the computational flow loops back to the CFD analysis and the other geometrical parameters of the collector are set. The loop continues until allowable stresses in the construction are exceeded. If the maximum stress is lower than the critical stress, the construction is safe to use, and the computations stop.

The methodology presented in the paper may help to assess structural safety. The computations described in this chapter were successfully applied in analysis of two failures of a high performance heat exchanger that happened in an industrial company in Poland.

\section{Hydraulic and thermal performance of heat exchanger}

The proper operating conditions of the high performance heat exchanger improve its thermal efficiency and lead to significantly smaller pressure exerted on tube material.

The operating conditions depend strongly on flow distribution inside the tubes of the high performance heat exchanger. The main task of hydraulic computation is to confirm, that liquid flowing inside the tubes is distributed properly in all the tubes. It is ideally, when the mass flow rate $\dot{m}$ in each tube equals to the mass flow at the inlet $\dot{m}_{i n}$ divided by the number of tubes $n$ in a single pass of the heat exchanger. Nevertheless, it is impossible in fact to obtain the uniform flow distribution in all the tubes. The improper flow distribution has an influence on heat transfer process in each pass of the heat exchanger, causing high temperature differences in the adjacent tubes that can cause the stress limit of the tube material to be exceeded. 
The heat exchanger, for which the computations are carried out, is presented schematically on Fig. 4.

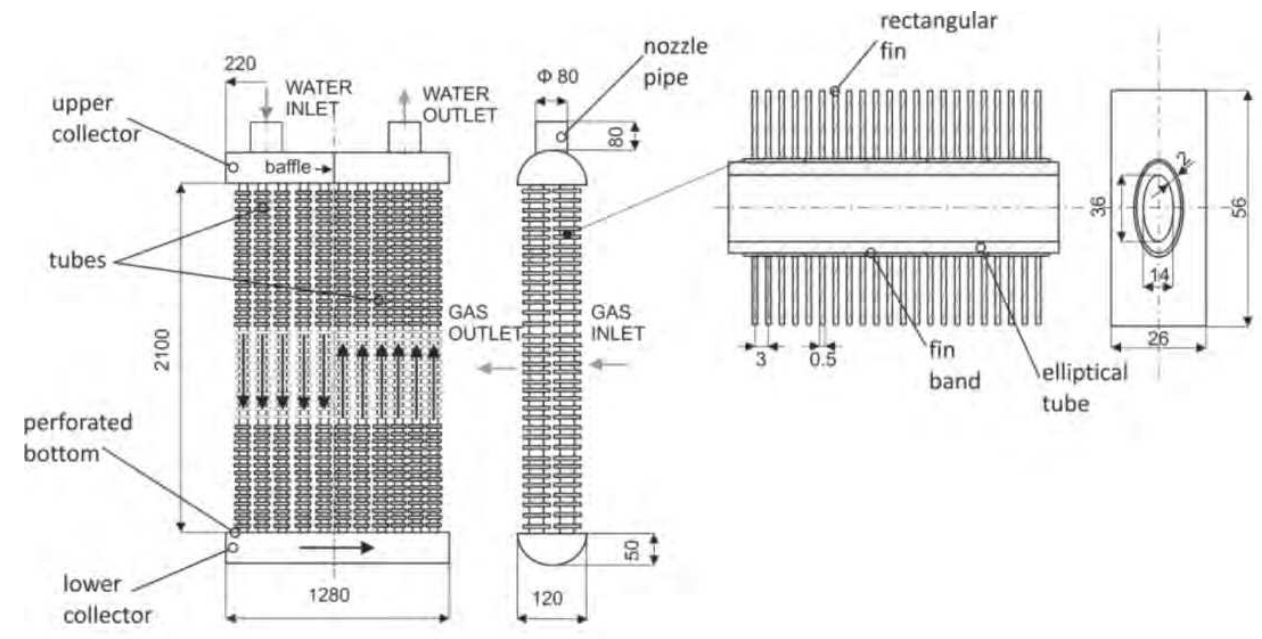

Fig. 4. Scheme of a two pass high performance heat exchanger

The operating conditions of the heat exchanger, as presented on Fig. 4, are listed in Tab. 1:

\begin{tabular}{|c|c|c|}
\hline Name & Symbol & Value, Unit \\
\hline Mass flow rate of water & $\dot{m}_{\text {wat }}$ & $\begin{array}{c}19 \mathrm{~kg} / \mathrm{s}, 14 \mathrm{~kg} / \mathrm{s}, \\
9.5 \mathrm{~kg} / \mathrm{s}\end{array}$ \\
\hline Velocity of combustion gas & $w_{c g-\text { in }}$ & $4 \mathrm{~m} / \mathrm{s}$ \\
\hline $\begin{array}{c}\text { Number of tubes } \\
\begin{array}{c}\text { Inlet and outlet temperature } \\
\text { of water }\end{array}\end{array}$ & $T_{\text {wat-in }} / T_{\text {wat-out }}$ (max value) & 42 \\
\hline $\begin{array}{c}\text { Inlet and outlet temperature } \\
\text { of combustion gas }\end{array}$ & $T_{c g-\text { inlet }} / T_{c g-o u t l e t}($ min value) & $410 / 130^{\circ} \mathrm{C}$ \\
\hline $\begin{array}{c}\text { Operating pressure for } \\
\text { water }\end{array}$ & $p_{\text {op }}$ & $6 \mathrm{bar}$ \\
\hline
\end{tabular}

Table 1. Operating conditions for the analysed high performance heat exchanger

Working principle of the analysed heat exchanger is to cool rapidly combustion gas. Heat is transferred from hot gas to water which flows into the device through the inlet nozzle pipe at the mean temperature $T_{\text {wat-in }}=110^{\circ} \mathrm{C}$. Water fills in the upper part of the collector. Next, it is distributed in the 1 st pass to $n=42$ tubes of the heat exchanger, where it flows down to the lower collector. Then, it turns back and flows through the other part of the tubes (2nd pass of the heat exchanger) into the upper collector and finally leaves the device through the outlet nozzle pipe with the mean temperature $T_{\text {wat-out }}$, that equals to no more than $130^{\circ} \mathrm{C}$. The tubes are arranged into two rows. Combustion gas, with the mean inlet temperature 
$T_{c g \text {-inlet }}=450{ }^{\circ} \mathrm{C}$ flows perpendicularly to the tubes, exchanging heat with the first row of the tubes and subsequently with the second one. Finally, it leaves the device cooled to no less than $T_{c g \text {-outlet }}=350{ }^{\circ} \mathrm{C}$. Later, the gas is cooled to $100{ }^{\circ} \mathrm{C}$ in other heat exchangers (not shown here) and released to the atmosphere. The presented heat exchanger is a part of the installation where the largest thermal stresses may occur, so its failure is most probable to happen.

\subsection{Numerical model of flow around finned elliptical tube}

Analysis of flow dynamic and heat transfer is divided into two parts. First, heat transfer from combustion gas to the tube is modelled, next the flow of water inside the heat exchanger is analysed, knowing the thermal boundary conditions - heat transfer coefficient and bulk temperature distribution on the outer surface of the tube. Discretization of flow domain (lower case) and boundary condition types (uppercase) for analysis of the flow around the finned elliptical tube are presented on Fig. 5.

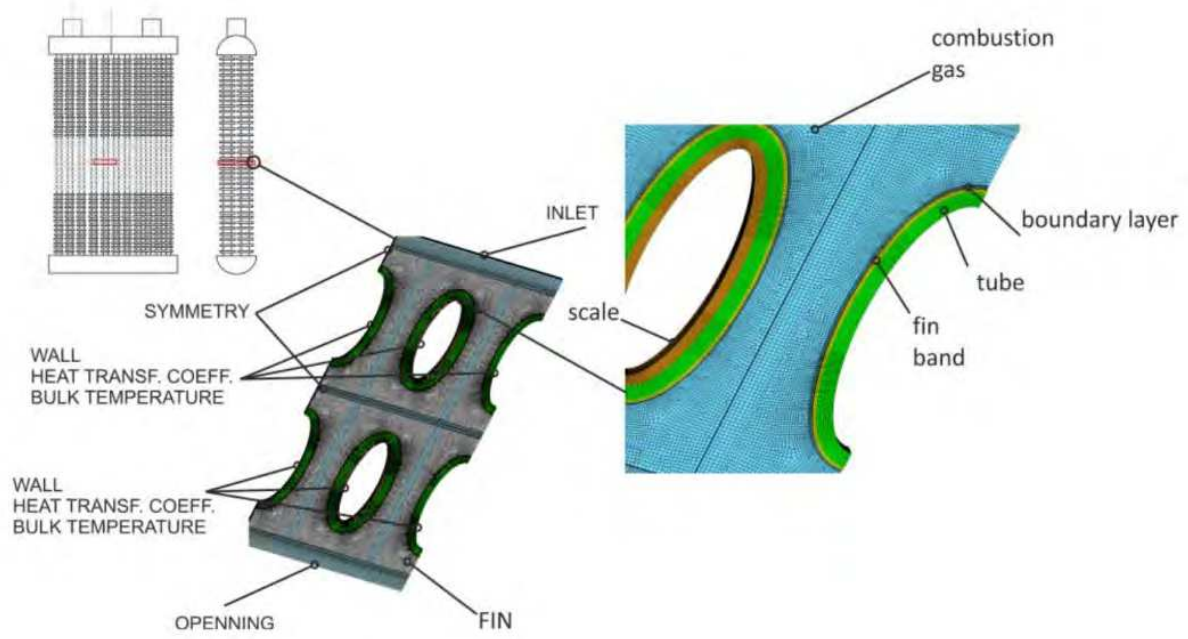

Fig. 5. Numerical model of flow around finned elliptical tube

The combustion gas is modelled as an ideal gas with density $\rho_{c g}=3 \mathrm{~kg} / \mathrm{m}^{3}$ and dynamic viscosity $\eta_{c g}=27 \cdot 10^{-6} \mathrm{~Pa} / \mathrm{s}$. Mass, momentum and energy equation (Bird, 2001) are used in computation. In order to model the turbulence, the SST (shear-stress transport) transport equations (Egorov \& Menter, 2008) are used in the CFD analysis. The mixed boundary condition simulates the heat transfer from water to a tube. The bulk temperature of water $T_{\text {wat-b }}$ is assumed to be equal $T_{\text {wat-out }}$ and the heat transfer coefficient $h_{\text {wat }}$ is calculated, knowing the mean velocity in a tube, which is calculated according to the following formula:

$$
\overline{w_{\text {wat }}}=\frac{\dot{m}_{\text {wat }}}{n \cdot A_{\text {tube }} \cdot \rho_{\text {wat }}},
$$

where $A_{\text {tube }}$ is equal to the area of flow through an elliptical duct and $\rho_{\text {wat }}$ is the density of water calculated for $T_{w a t-b}$.

The Nusselt Number of water $\mathrm{Nu}_{\text {wat }}$ is calculated according to (Gnielinski, 1976): 


$$
\mathrm{Nu}_{\text {wat }}=\frac{\frac{1}{8} \cdot f \cdot\left(\mathrm{Re}_{\text {wat }}-1000\right) \cdot \mathrm{Pr}_{\text {wat }}}{1+12.7 \cdot\left(\frac{1}{8} \cdot f\right)^{\frac{1}{2}} \cdot\left(\mathrm{Pr}_{\text {wat }}^{\frac{2}{3}}-1\right)} .
$$

It was stated in the paper (Łopata \& Ocłon, 2010), that velocity of water in this type of a heat exchanger can be significantly different for tubes in the $1^{\text {st }}$ and in the $2^{\text {nd }}$ pass of the high performance heat exchanger. The zones and locations in the tube were indicated where mean velocity is over 20 times lower than in the other tubes. The thermal load is significantly larger in those zones than in the ones with proper velocity distribution. Moreover, low velocities of liquid favour deposition of boiler scale (Najibi et al., 2007; Quan et al., 1997; Nebot et al., 2007; Freeborn \& Lewis, 1962), especially when water is not prepared properly that causes the flow resistance growth. Consequently, water velocity decreases even more. With regard to the above, it is not the average velocity of water, but the $w_{w a t}=1 / 2 \cdot \bar{w}_{\text {wat }}$ that is used to calculate the Reynold's number of water - $\operatorname{Re}_{\text {wat }}$. It simulates the real operating conditions of a device, when scale starts to deposit inside the tube and thermal load increases significantly.

The Prandtl number of water $\operatorname{Pr}_{w a t}$ is obtained for the specific heat capacity $c_{p \text {-wat }}$, dynamic viscosity $\eta_{w a t}$ and thermal conductivity $k_{w a t}$ of water that on the turn are measured at bulk temperature equal to $T_{w a t-b}$ :

$$
\operatorname{Pr}_{w a t}=\frac{c_{p-w a t} \cdot \eta_{w a t}}{k_{w a t}}
$$

The Darcy friction factor $f$ is calculated according to formula (White, 2003):

$$
f=\left(0.79 l n \cdot \operatorname{Re}_{w a t}-1.64\right)^{-2} .
$$

Finally $h_{w a t}$ is computed as follows:

$$
h_{w a t}=\frac{\mathrm{Nu}_{w a t} \cdot k_{w a t}}{d_{h}} .
$$

The equivalent diameter $d_{h}$ of an elliptical tube is computed according to the following dependence:

$$
d_{h}=\frac{4 \cdot A_{\text {tube }}}{P_{\text {tube }}},
$$

where $P_{\text {tube }}$ is equal to the perimeter of an elliptical duct. The values of $h_{\text {wat }}$, obtained from eq. (5) and $T_{w a t-b}$ for all the computational cases are listed in Table 2.

\begin{tabular}{|c|c|c|}
\hline$\dot{m}_{\text {wat }}[\mathrm{kg} / \mathrm{s}]$ & $h_{\text {wat }}\left[\frac{\mathrm{W}}{\mathrm{m}^{2} \cdot \mathrm{K}}\right]$ & $T_{\text {wat }-b}\left[{ }^{\circ} \mathrm{C}\right]$ \\
\hline 19 & 3630 & 130 \\
\hline 14 & 2720 & 130 \\
\hline 9.5 & 1815 & 130 \\
\hline
\end{tabular}

Table 2. Values of $T_{w a t-b}$ and $h_{w a t}$ used in analysis of flow around finned elliptical tube

The cross - section of the tube, which fractured during the device operation, is presented on Fig. 6. It is possible to observe deposition of scale on the inner surface of the tube. For computational cases, two thicknesses of scale $t_{s}=1 \mathrm{~mm}$ and $1.5 \mathrm{~mm}$ are analysed. Thermal conductivity of scale depends on quantity of calcium carbonate (Najibi et al. 1997). The thermal conductivity of boiler scale is assumed to be equal to $0.1 \mathrm{~W} /(\mathrm{m} \mathrm{K})$ for the present 
computation that models the location of the fracture. Scale deposition is modelled only for the tubes in the middle of computational domain, because the existence of scale in neighbouring tubes wasn't noticed during the site inspection.

It is possible to observe, on the outer wall of the elliptical tube, the layer of fouling that also influences heat transfer inside the device, worsening considerably thermal contact between the fin and the tube.

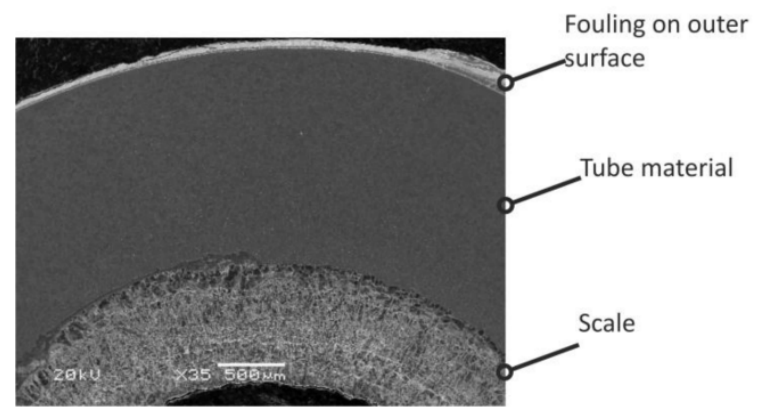

Fig. 6. Picture of damaged tube (cross - section)

This layer is modelled in ANSYS CFX as thermal resistance on the interface between the fin band and the tube. Thickness of material is assumed to be $0.1 \mathrm{~mm}$ and its thermal conductivity equals to $1 \mathrm{~W} /(\mathrm{m} \mathrm{K})$.

Heat flux density $\dot{q}$ is computed on the interface between the tube (Fig. 7) and the fin band so that the interface area is divided into $n_{\text {int }}=40$ intervals along the $y$ direction.

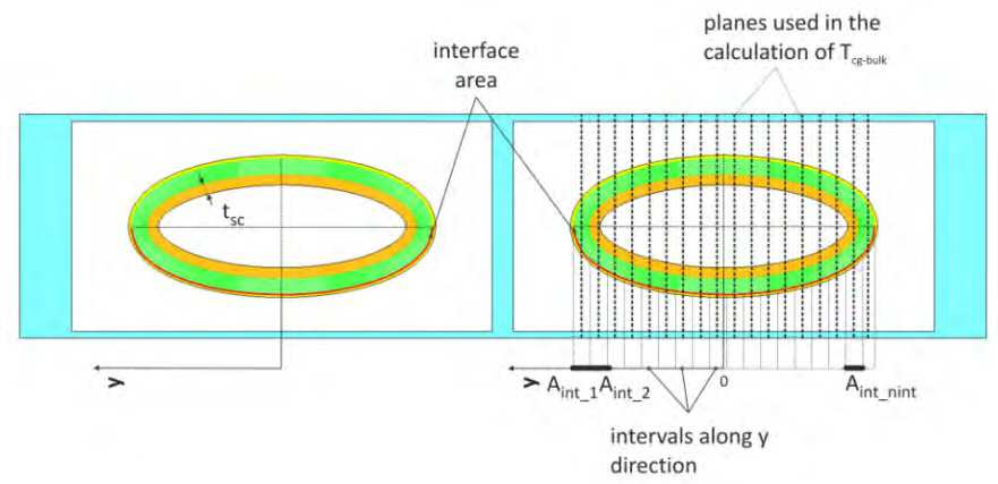

Fig. 7. Division of interface area into intervals

For the $n_{e l}$ number of elements that belong to each of the $y$ intervals the area averaged heat flux is computed as follows:

$$
\dot{q}_{\text {int }}=\frac{\sum_{j=1}^{n_{e l} l} q_{j} \cdot A_{j}}{\sum_{j=1}^{n_{e l}} A_{j}} .
$$

The area averaged wall temperature is calculated according to the formula: 


$$
T_{\text {wall }}=\frac{\sum_{j=1}^{n_{e l} l} T_{j} \cdot A_{j}}{\sum_{j=1}^{n} A_{j}} .
$$

The mass flow averaged temperature is computed in the middle of each $y$ interval:

$$
T_{c g-b u l k}=\frac{\sum_{j=1}^{n_{e l} T_{j}} \cdot \dot{m}_{j}}{\sum_{j=1}^{n_{e l} l} \dot{m}_{j}} .
$$

Knowing values of the area averaged heat flux density for each interval $\dot{q}_{\text {int }}$, the area averaged wall temperature for intervals $T_{\text {wall }}$ and the bulk temperature computed in the middle of interval $T_{c g-b u l k}$, the heat transfer coefficient from combustion gas to the tube is determined according to the formula:

$$
h_{c g}(y)=\frac{\dot{q}_{\text {int }}}{\left(T_{c g-\text { bulk }}-T_{\text {wall }}\right)}
$$

The sample results presented below were obtained for $\dot{m}_{w a t}=19 \mathrm{~kg} / \mathrm{s}$. The bulk temperature and heat transfer coefficient distribution for all the $\dot{m}_{w a t}$ values listed in Table 2 are used as the thermal boundary condition for analysis of flow distribution inside the high performance heat exchanger.

On Figure 8 temperature and velocity distribution is presented when combustion gas flows around the finned elliptical tube.

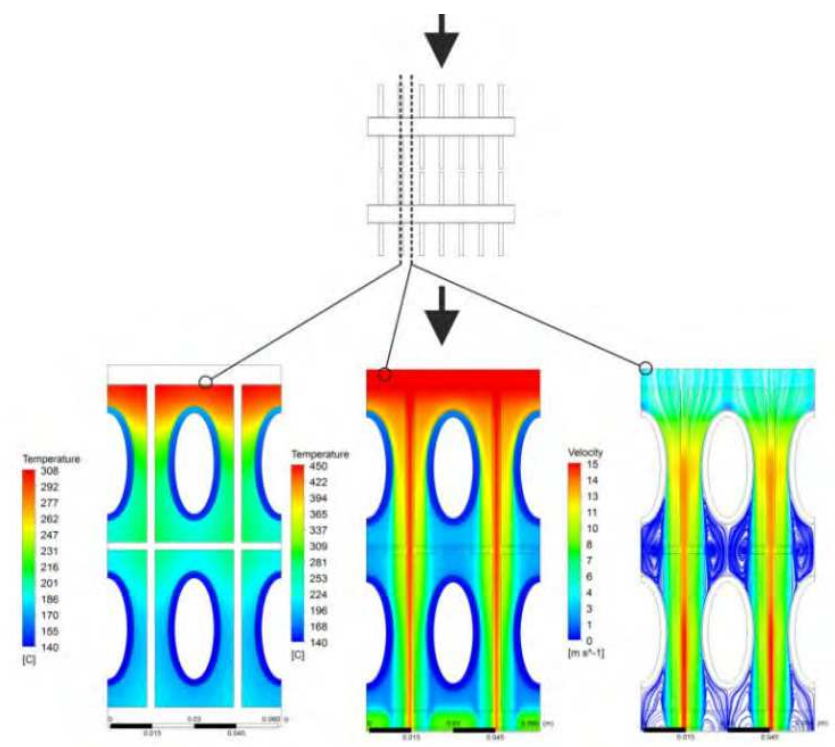

Fig. 8. Temperature and velocity distribution for $t_{s}=0 \mathrm{~mm}$

It is possible to observe, that the stagnation zones occur under the $1^{\text {st }}$ row as well as above and under the $2^{\text {nd }}$ row of tubes. Therefore the fins don't operate properly, and the largest amount of heat is transferred only to the $1^{\text {st }}$ row of tubes. It may lead to high temperature differences on the circumference of the tubes and consequently may cause significant bending stresses to the tube. 
The temperature distribution in the fin and in gas for $t_{s}=1 \mathrm{~mm}$ is presented on Fig 9. The boiler scale deposition significantly increases temperatures of the tube and the fin. Consequently thermal loading of the tubes in this case is considerably greater than when $t_{s}=0 \mathrm{~mm}$.
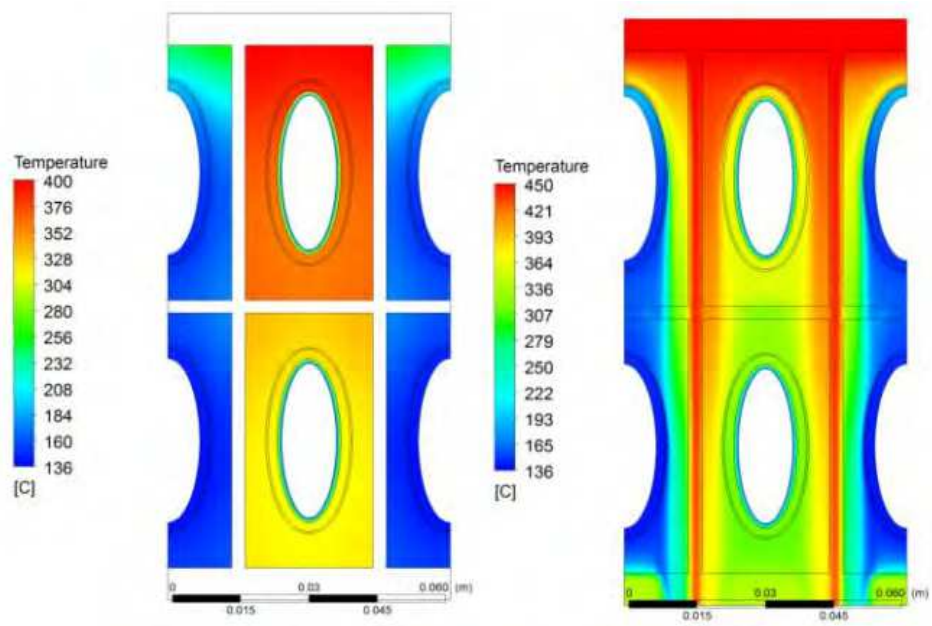

Fig. 9. Temperature distribution for $t_{s}=1 \mathrm{~mm}$

Increase in scale thickness from $1 \mathrm{~mm}$ to $1.5 \mathrm{~mm}$ (see Fig. 10) causes the temperature of the tube, the fin and combustion gas to grow up. It is evident that boiler scale reduces heat flux from combustion gas to water, causing temperature of the fins and the tube to increase. This effect is more pronounceable with increase in boiler scale thickness.
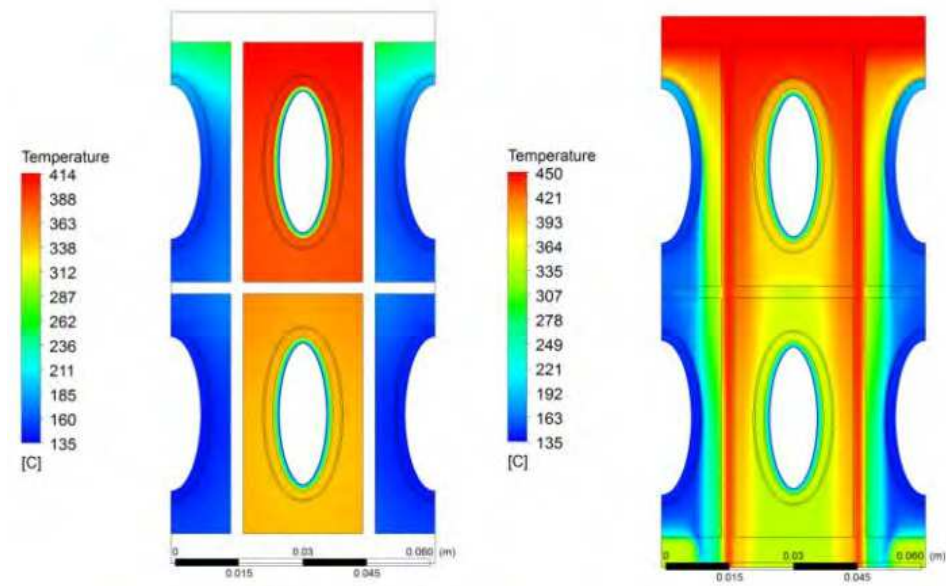

Fig. 10. Temperature distribution for $t_{s}=1.5 \mathrm{~mm}$ 
On Fig. 11 the $h_{c g}$ and $T_{c g-b u l k}$ distribution along $y$ direction for $t_{s}$ is presented
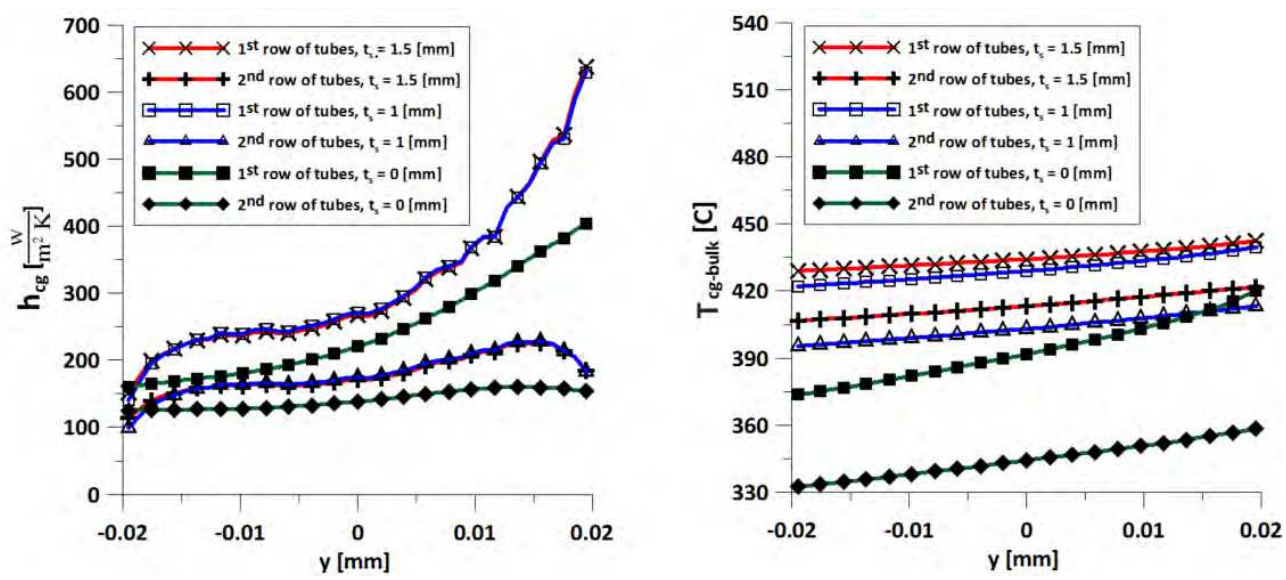

Fig. 11. Heat transfer coefficient and bulk temperature distribution for combustion gas $-t_{s}=$ $0 \mathrm{~mm}, t_{s}=1 \mathrm{~mm}$ and $t_{s}=1.5 \mathrm{~mm}$

Heat transfer coefficient from combustion gas to the tube is larger when boiler scale thickness increases. Rapid growth of $T_{\text {cg-bulk }}$ combined with isolative behaviour of scale, causes high temperature increase of the tube. Therefore, operating condition of the device worsens significantly, because the normal stresses acting on the tube grow up with increase in temperature, too.

\subsection{Flow distribution inside collectors and tubes of high performance heat exchanger}

Analysis of flow distribution inside the high performance heat exchanger is carried out using the mass, momentum and energy balance equations (Bird, 2001; Incopera \& De Witt, 2001). The turbulence model SST is applied to flow behaviour simulation. The numerical model of the flow is presented on Fig. 12.

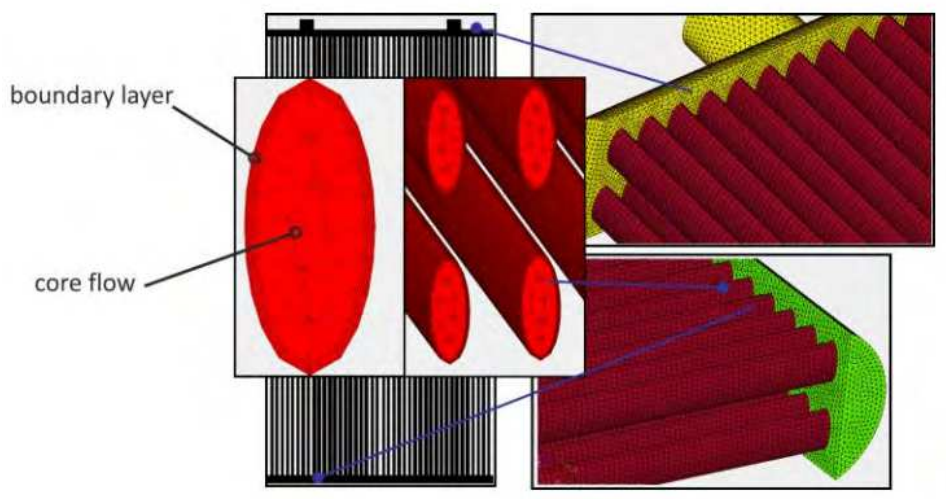

Fig. 12. Numerical model used for analysis of flow distribution inside heat exchanger 
The boundary layer is modelled using the hexahedral elements and the flow core is discretized using the tetrahedral elements. The boundary conditions set for $\dot{m}_{w a t}=19 \mathrm{~kg} / \mathrm{s}$ is presented on Fig. 13.
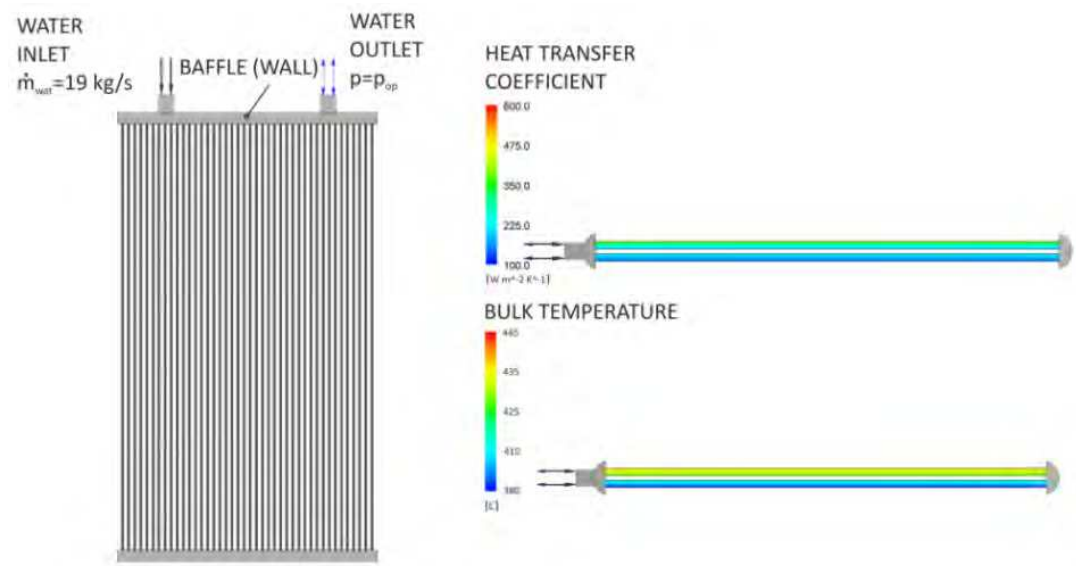

Fig. 13. Boundary condition for analysis of water flow $-\dot{m}_{w a t}=19 \mathrm{~kg} / \mathrm{s}$

As mentioned in section 1 , it is difficult to ensure the uniform flow distribution to all the tubes, due to limited space in the collectors. The zones of the tubes where the velocity is significantly lower than the $\overline{w_{w a t}}$ are marked on red, see Fig. 14.

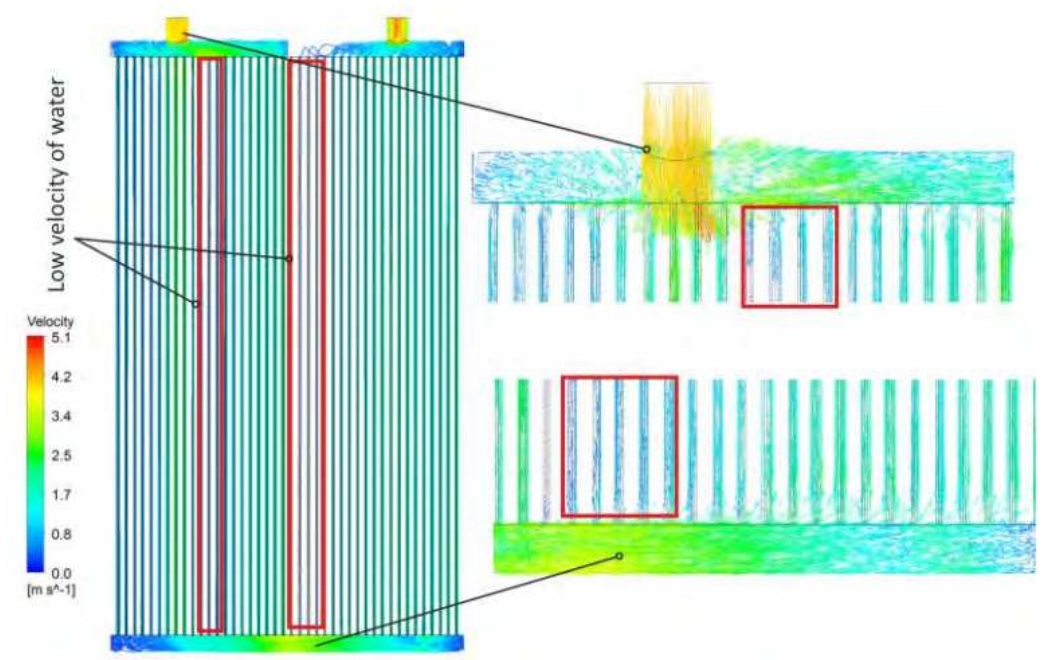

Fig. 14. Velocity distribution in high performance heat exchanger $-\dot{m}_{w a t}=19 \mathrm{~kg} / \mathrm{s}$ 
These zones are formed because pressure changes occur (see Fig. 15) in the direction parallel to the perforated bottom of the collector.

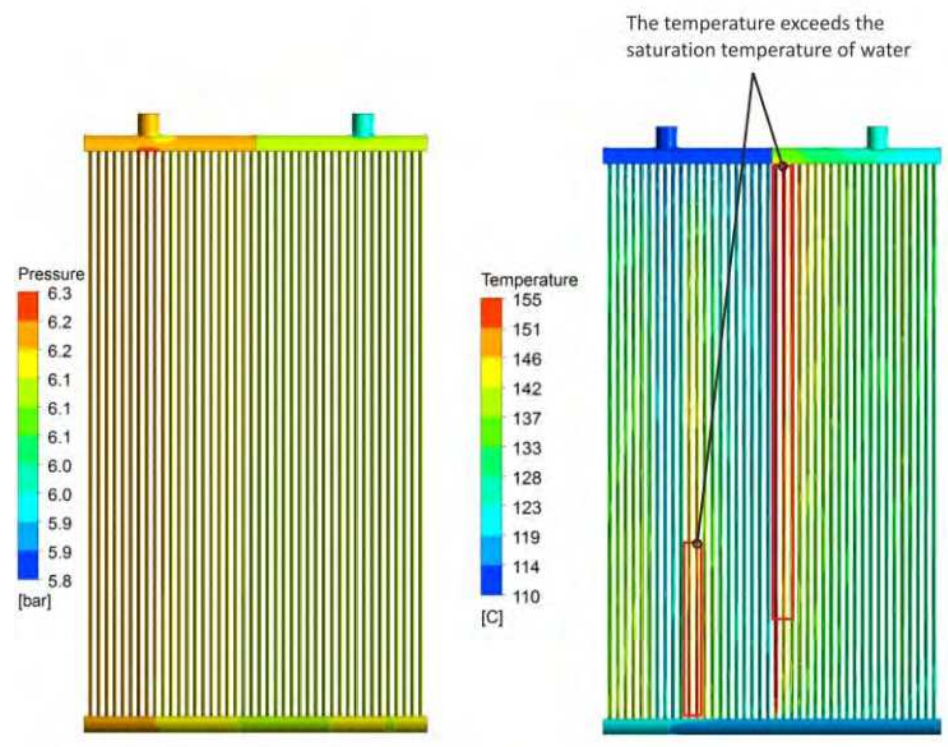

Fig. 15. Pressure and temperature distribution inside high performance heat exchanger $\dot{m}_{\text {wat }}=19 \mathrm{~kg} / \mathrm{s}$

The pressure is lower in the tubes with velocity bellow $\bar{w}_{w a t}$ than in the others. Therefore, the driving force of the flow falls down and liquid doesn't come into this segment of the tubes. E.g., in the first pass of the heat exchanger, liquid flows into the tubes of the heat exchanger, those are located directly under the inlet nozzle pipe. Velocity of liquid in these tubes is larger than $\overline{w_{w a t}}$. Amount of liquid flowing into the other tubes in this pass is much lower so are velocities. For the second pass of the heat exchanger, the component of velocity vector, parallel to the perforated bottom of the collector, is significantly larger than the other components. Therefore, due to the large inertia forces, water encounters difficulties when changing the flow direction by 90 degrees especially when entering the first tubes of the $2^{\text {nd }}$ pass of the heat exchanger. The mean velocity in tube $w$ (calculated as area averaged velocity) is the smallest there. It is even 20 times lower than the mean value (see Fig. 16).

Low flow velocities inside the tubes cause temperature of water to increase significantly. The zones and the locations where saturation temperature is exceeded are marked in red on Fig 15., the vapour bubbles starts to form there. When saturated steam flows inside the tube, the value $h_{w a t}$ increases rapidly. As a result, heat transfer conditions in the device change considerably and differ from the design predictions.

The ratio of average velocity in tube $w$, computed from numerical simulation, to mean velocity of water $\overline{w_{w a t}}$, presented on Fig. 16, shows that difficulties with improper flow distribution inside the heat exchanger exist in all the computational cases. For $\dot{m}_{w a t}=14$ 
$\mathrm{kg} / \mathrm{s}$ in the $2^{\text {nd }}$ pass of the heat exchanger, $w$ can be even 50 times smaller than $\overline{w_{w a t}}$, that can lead to fracture of the first tube near the axis of symmetry (2nd pass), because temperature increases and stress level exceeds the allowable limits. Therefore the construction of the collector should be modified to improve the ratios $w / \overline{w_{w a t}}$, for the $1^{\text {st }}$ and the $2^{\text {nd }}$ pass of the high performance heat exchanger.
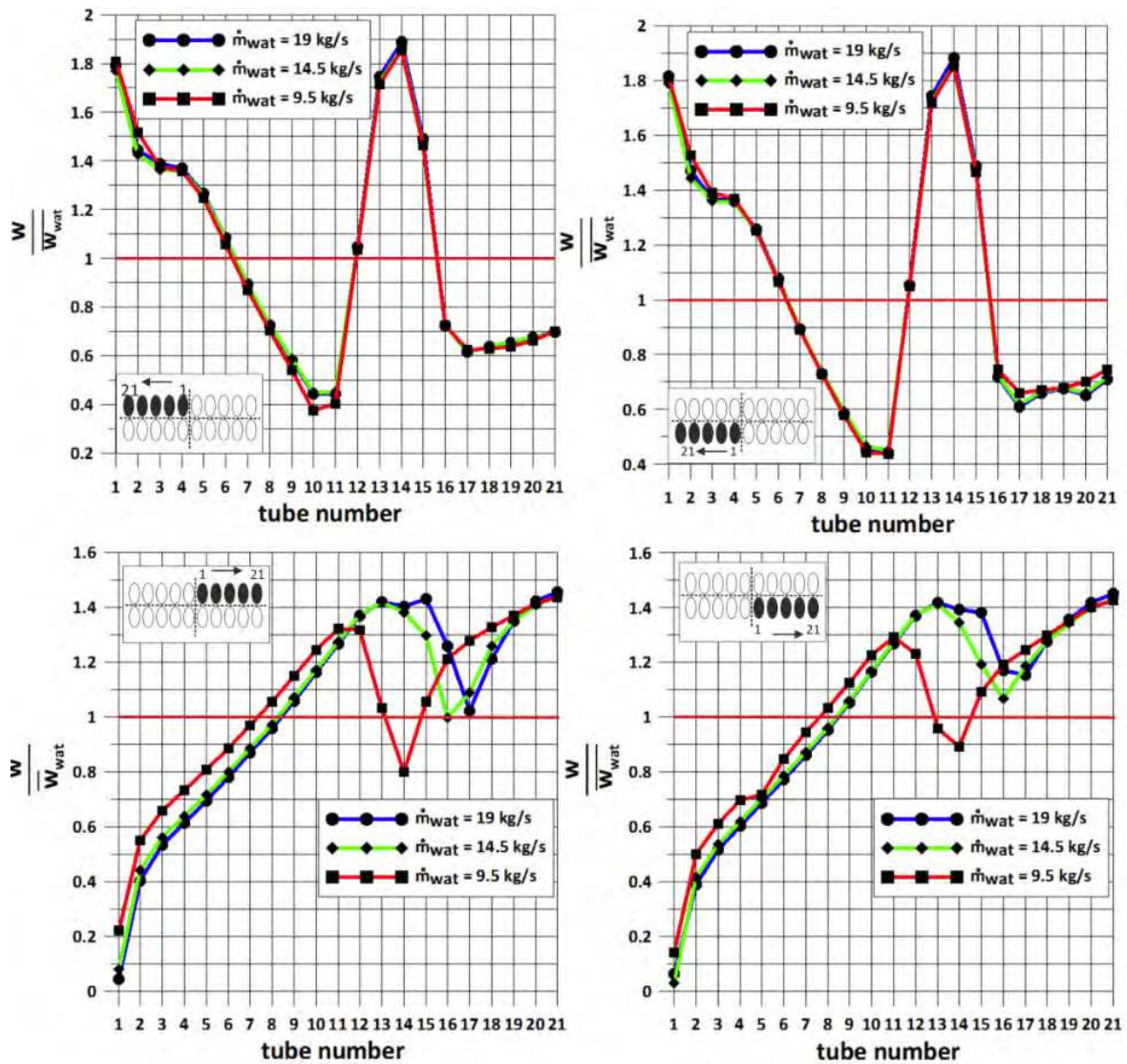

Fig. 16. Ratios of mean velocity in tube $w$ to estimated velocity $\overline{w_{w a t}}$ for $\dot{m}_{w a t}=9.5 \mathrm{~kg} / \mathrm{s}, 14$ $\mathrm{kg} / \mathrm{s}$ and $19 \mathrm{~kg} / \mathrm{s}$

The modified version of the collector is presented in the next subchapter.

\subsection{Analysis of flow distribution inside modified collector of high performance heat exchanger}

As mentioned before, difficulties in ensuring uniform flow velocity inside all the tubes of the high performance heat exchangers have forced us to find a new shape of the collector that improves flow distribution inside the tubes of the $1^{\text {st }}$ and the $2^{\text {nd }}$ pass. The shape of the collector, presented on Fig. 17, is being proposed. The greatest advantages of using it are its simplicity and low costs of manufacturing. 


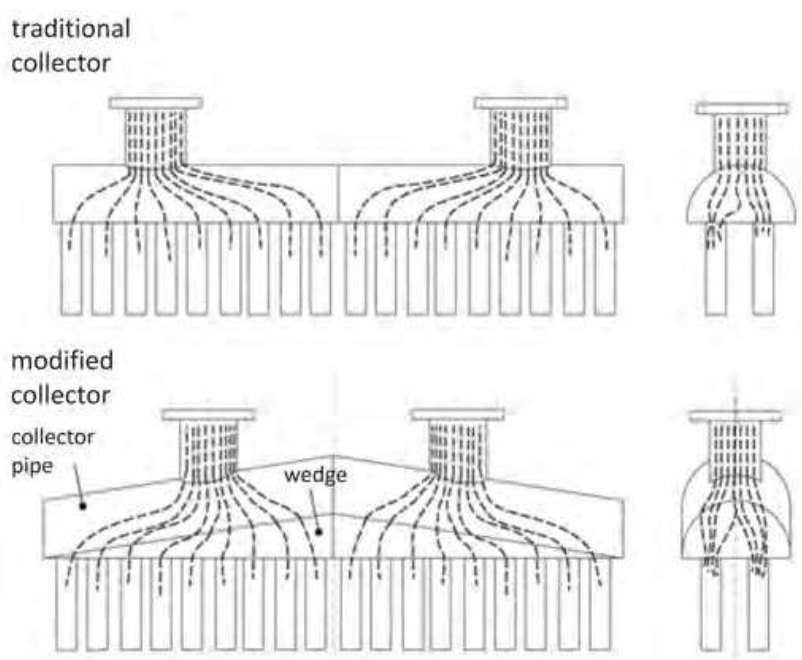

Fig. 17. Traditional and modified shape of collector

The wedge is being welded to the wall of the collector pipe. It increases flow space to enable the more uniform flow distribution inside all the tubes. It is the influence on flow distribution of three parameters (Fig. 18): the $h_{w}$, which is the height of wedge, the tube height $h_{t}$ and $x$ that is the distance between the side of collector and the axis of nozzle pipe, that are investigated.
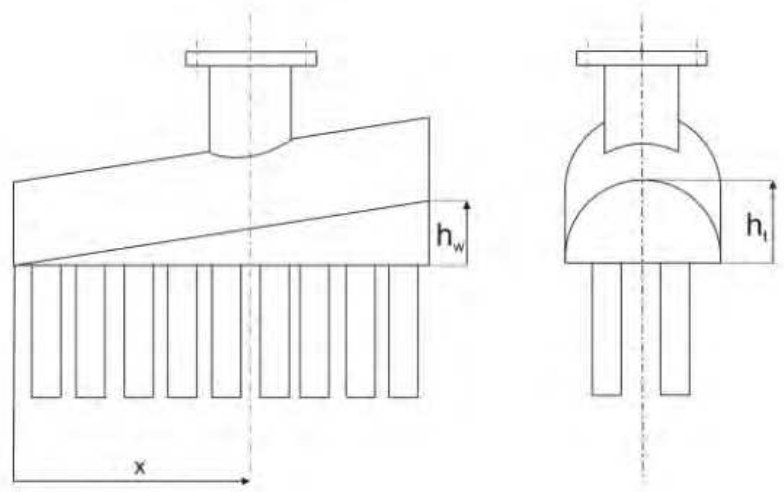

Fig. 18. Geometrical parameters of modified collector

The presented results from analysis are carried out for $\dot{m}_{w a t}=19 \mathrm{~kg} / \mathrm{s}$. The ratio of maximal velocity in the tube for the $1^{\text {st }}$ and the $2^{\text {nd }}$ pass of the heat exchanger to mean velocity of water in the tube $w_{\max } / \overline{w_{w a t}}$, as well as the ratio of minimal velocity for the $1^{\text {st }}$ and the $2^{\text {nd }}$ pass of the heat exchanger to mean velocity of water in the tube $w_{\min } / \overline{w_{w a t}}$ can be observed on Fig. 19 for $h_{w}=40 \mathrm{~mm}$. 

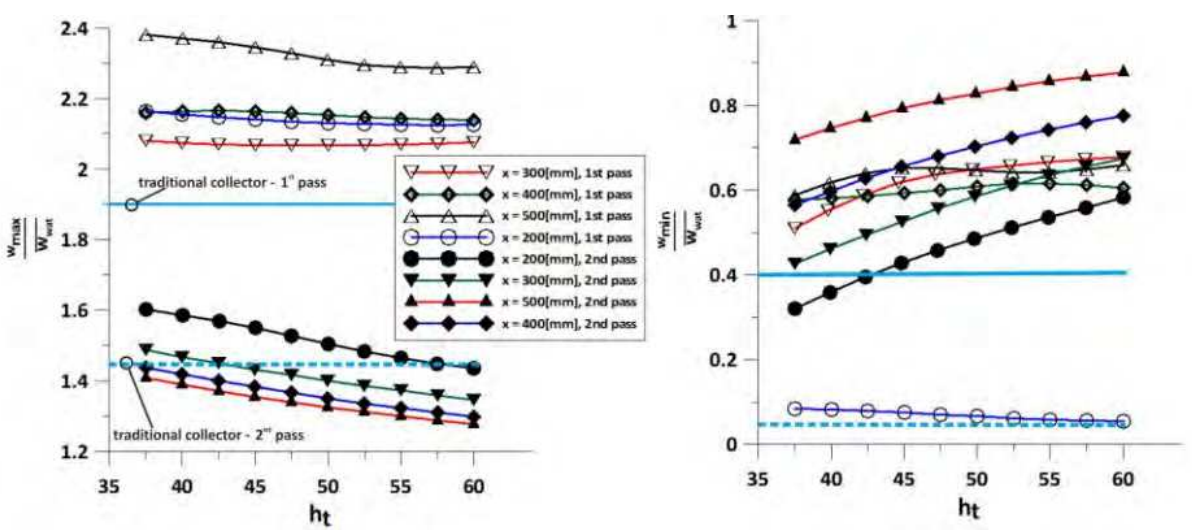

Fig. 19. Highest ratios of maximal and minimal velocity in tube $w_{\max }$ and $w_{\min }$ to $\overline{w_{w a t}}$ for $\dot{m}_{w a t}=19 \mathrm{~kg} / \mathrm{s}$ and $h_{w}=40 \mathrm{~mm}$.

The presented results show that it is difficult to obtain geometrical parameters of the collector for that the ratios $w_{\max } / \overline{w_{w a t}}$ and $w_{\min } / \overline{w_{\text {wat }}}$ are optimal for the $1^{\text {st }}$ and the $2^{\text {nd }}$ pass of the heat exchanger. For instance, the parameters $x=500 \mathrm{~mm}, h_{t}=38 \mathrm{~mm}$ and $h_{w}=40 \mathrm{~mm}$ ensure proper flow distribution to the $2^{\text {nd }}$ pass of the heat exchanger, but in the $1^{\text {st }}$ pass the ratio $w_{\text {max }} / \overline{w_{w a t}}$ has the highest value. For the presented case it is not as dangerous as low values of $w_{\text {min }} / \overline{w_{w a t}}$ for the construction; but when the function of the heat exchanger is to cool water, the large value of ratio $w_{\max } / \overline{w_{w a t}}$ is not desired. The worst results are for $x=$ $200 \mathrm{~mm}, h_{t}=60 \mathrm{~mm}$ and $h_{w}=40 \mathrm{~mm}$, when the ratio $w_{\min } / \overline{w_{w a t}}$ equals 0.05 for the 1 st pass of the heat exchanger. In the case of heating the medium that flows inside the heat exchanger it can bring about significant compressible stresses acting on the tube.

The results obtained for $h_{w}=50 \mathrm{~mm}$ doesn't differ significantly from the previously presented. However, it is possible to observe on Fig. 20 that for the $1^{\text {st }}$ pass of the heat exchanger the ratio $w_{\min } / \overline{w_{w a t}}$ is lower for $x=500 \mathrm{~mm}$ than for the same values of $\mathrm{x}$ and $h_{t}$ if $h_{w}=40 \mathrm{~mm}$. This means, that the increase in $h_{w}$ from $40 \mathrm{~mm}$ to $50 \mathrm{~mm}$ doesn't improve the flow condition inside the device considerably.
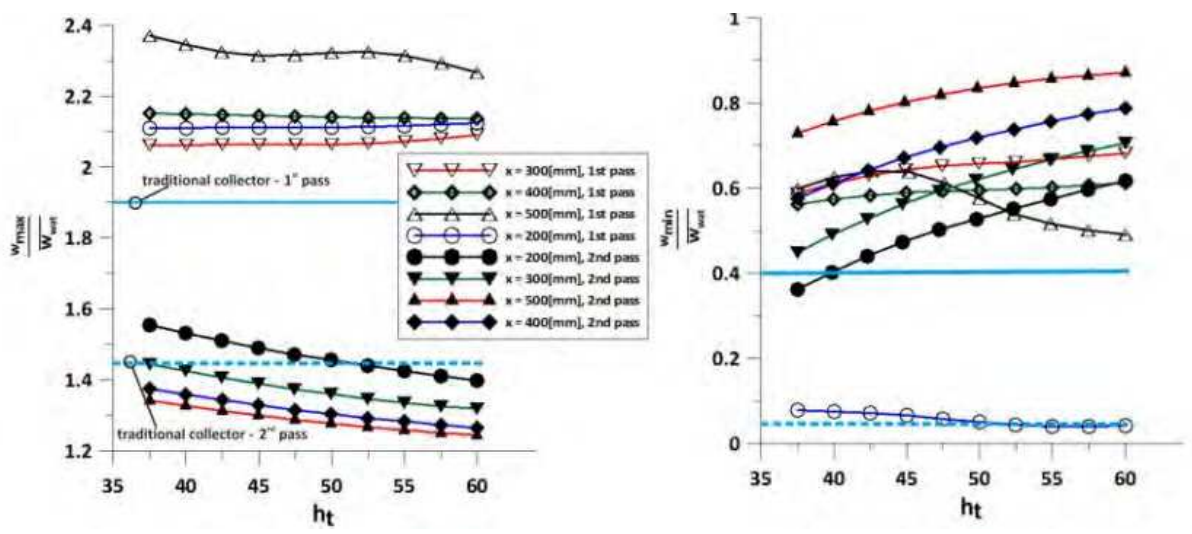

Fig. 20. Highest ratios of maximal and minimal velocity in tube $w_{\max }$ and $w_{\min }$ to estimated velocity $\overline{w_{\text {wat }}}$ for $\dot{m}_{\text {wat }}=19 \mathrm{~kg} / \mathrm{s}$ and $h_{w}=50 \mathrm{~mm}$. 
The results for $h_{w}=60 \mathrm{~mm}$ are shown on the Fig. 21. Extreme positioning of the nozzle pipe: $x=200 \mathrm{~mm}$ and $x=500 \mathrm{~mm}$ causes improper flow distribution for the $1^{\text {st }}$ pass of the heat exchanger.
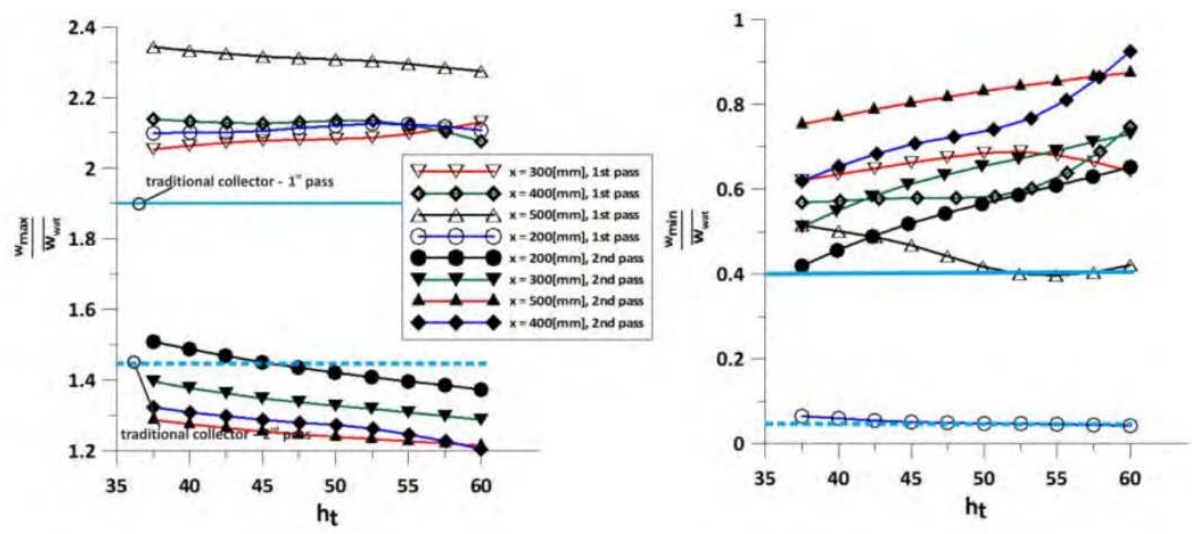

Fig. 21. Highest ratios of maximal and minimal velocity in tube $w_{\max }$ and $w_{\min }$ to estimated velocity $\bar{w}_{w a t}$ for $\dot{m}_{w a t}=19 \mathrm{~kg} / \mathrm{s}$ and $h_{w}=60 \mathrm{~mm}$.

The last set of results, Fig. 22, is presented for $h_{w}=70 \mathrm{~mm}$. In contrary to the results presented before, increasing $h_{w}$ with increasing $h_{t}$ up to $55 \mathrm{~mm}$, improves $w_{\text {min }} / \bar{w}_{\text {wat }}$ in the $1^{\text {st }}$ pass of the heat exchanger for $x=200 \mathrm{~mm}$. The largest improvement is in ratio $w_{\min } / \overline{w_{w a t}}$ especially for the $1^{\text {st }}$ pass, that is 0.4 for $x=200 \mathrm{~mm}$.
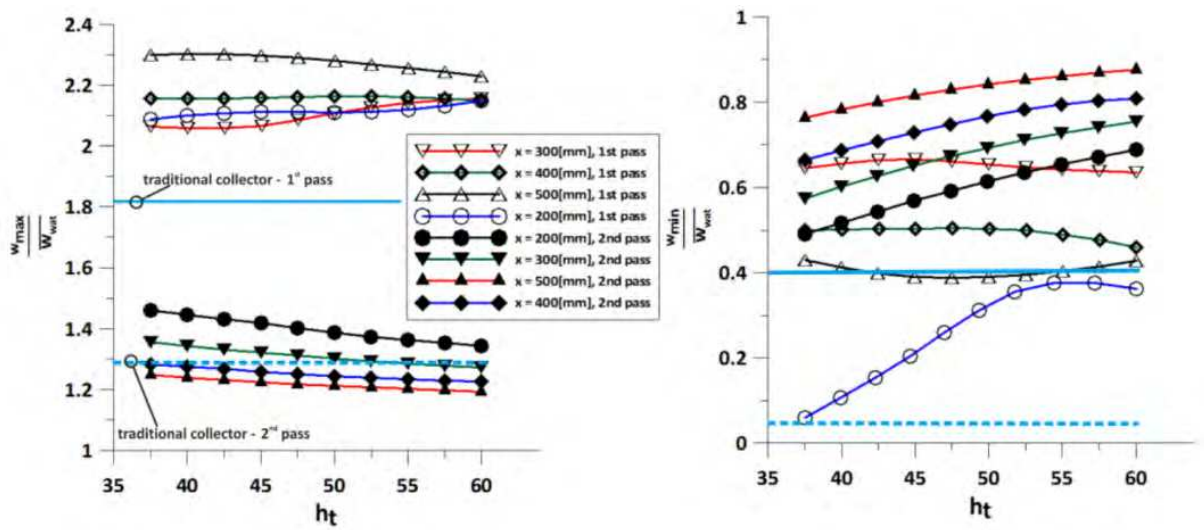

Fig. 22. Highest ratios of maximal and minimal velocity in tube $w_{\max }$ and $w_{\min }$ to estimated velocity $\bar{w}_{w a t}$ for $\dot{m}_{w a t}=19 \mathrm{~kg} / \mathrm{s}$ and $h_{w}=70 \mathrm{~mm}$.

All of the presented results show that it is difficult to find optimal solution for geometry presented on Fig.18. However, it is possible to reach compromise between large values of $w_{\max } / \overline{w_{w a t}}$ and low values of $w_{\min } / \overline{w_{\text {wat }}}$, e.g. for the set of parameters $x=300 \mathrm{~mm}, h_{w}=40$ $\mathrm{mm}$ and $h_{t}=55 \mathrm{~mm}$. In the $1^{\text {st }}$ pass of the heat exchanger, the $w_{\text {max }} / \overline{w_{\text {wat }}}$ is slightly larger than for the traditional collector. However, the biggest advantage of using the modified shape of the collector, with the mentioned parameters is that the $w_{\min } / \overline{w_{w a t}}$ is similar for both the $1^{\text {st }}$ 
and the $2^{\text {nd }}$ pass of the heat exchanger and doesn't exceed 0.6 . Therefore the differences in the wall temperature will be not as large as for the traditional shape of the collector.

\section{Temperature distribution inside elliptical tube}

Numerical code in $c^{++}$has been written for the thermal analysis, in order to obtain temperature distribution inside the elliptical tube. The boundary condition for this analysis is taken from the CFD computation (water flow distribution inside the tubes). On the outer surface of the elliptical tube, the $h_{c g}$ and $T_{c g-b u l k}$ values are applied. On the inner surface of the elliptical tube, the $h_{w a t}$ values obtained for the CFX calculated mass flow rate and mass flow averaged temperature in each tube are taken into computation. If it is necessary, the code can incorporate the boiler scale layer into calculation, as well as fouling resistance on the outer surface of the tube.

The results obtained from thermal analysis for all the tubes are then used as the thermal loading in structural analysis.

Temperature distribution inside the elliptical tube is obtained in the Finite Volume Method via the Finite Element Method (Taler \& Duda, 2006; Chang, 2010). The two-dimension steady state heat transfer is assumed; therefore the isoparametric linear quadrilateral elements (Chang, 2010, Lewis, 2004) are applied. The isoparametric element creating the control volume is presented on Fig. 23.

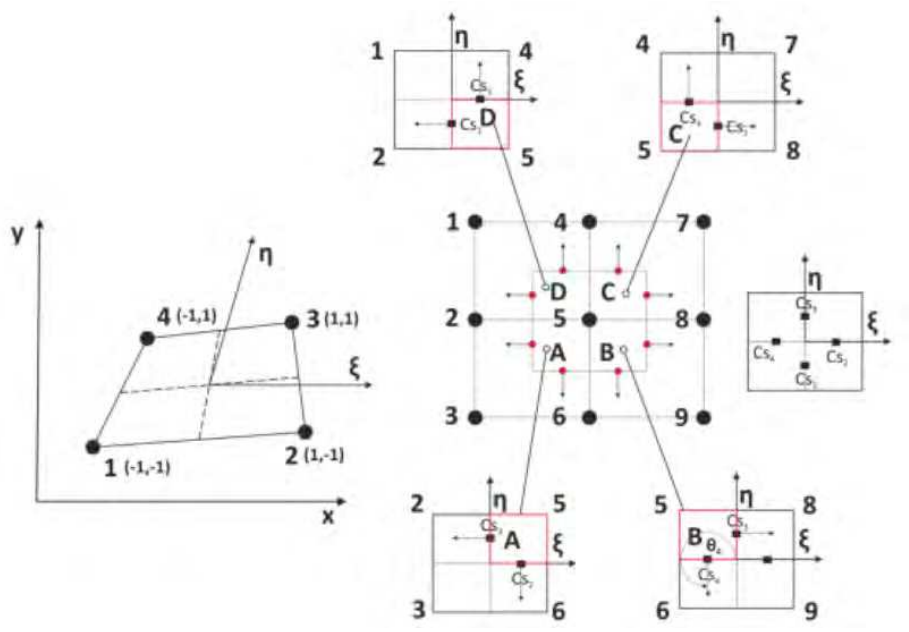

Fig. 23. Finite Volume Method via Finite Elements

The real coordinates $(x, y)$ are mapped into the natural coordinates $(\xi, \eta)$. Therefore, the quadrilateral element can be treated as the rectangular element. The lines connecting the middles of the rectangle sides and the nodes of the quad element create the sub-control volumes, as presented on Fig. 23. Four sub-control volumes create one large control volume. Each sub-control volume is also treated as the quadrilateral isoperimetric element; therefore, the shape functions are applied to approximate temperature distribution and coordinates inside the quad element. For the isoperimetric elements, the temperature distribution inside the element domain is estimated, using the following shape function (Taler \& Duda, 2006): 


$$
\begin{aligned}
& \Phi_{1}^{e}=\frac{1}{4} \cdot(1-\xi) \cdot(1-\eta) \\
& \Phi_{2}^{e}=\frac{1}{4} \cdot(1+\xi) \cdot(1-\eta) \\
& \Phi_{3}^{e}=\frac{1}{4} \cdot(1+\xi) \cdot(1+\eta) \\
& \Phi_{4}^{e}=\frac{1}{4} \cdot(1-\xi) \cdot(1+\eta)
\end{aligned}
$$

Temperature inside the element is obtained by multiplying the nodal temperature $T_{i}$ and the function $\Phi_{\mathrm{i}}^{\mathrm{e}}$ that corresponds to the node shape:

$$
T(\xi, \eta)=\sum_{i=1}^{4} T_{i} \cdot \Phi_{i}^{e}
$$

The $x$ and $y$ coordinates inside the element domain are interpolated in a similar manner as temperature:

$$
\begin{aligned}
& x=\sum_{i=1}^{4} x_{i} \cdot \Phi_{i}^{e} \\
& y=\sum_{i=1}^{4} y_{i} \cdot \Phi_{i}^{e}
\end{aligned}
$$

As mentioned before, the control volume consists of four sub-control volumes A, B, C, D. The heat flux balance for the control volume can be written in the form:

$$
\begin{gathered}
k_{A} \cdot \sum_{C s 2,3}\left(\frac{d T}{d x} \cdot n_{x}+\frac{d T}{d y} \cdot n_{y}\right) \cdot \overrightarrow{\Delta \Gamma}+k_{B} \cdot \sum_{C s 3,4}\left(\frac{d T}{d x} \cdot n_{x}+\frac{d T}{d y} \cdot n_{y}\right) \cdot \overrightarrow{\Delta \Gamma}+y=\sum_{i=1}^{4} y_{i} \cdot \Phi_{i}^{e} \\
k_{c} \cdot \sum_{C s 4,1}\left(\frac{d T}{d x} \cdot n_{x}+\frac{d T}{d y} \cdot n_{y}\right) \cdot \overrightarrow{\Delta \Gamma}+k_{D} \cdot \sum_{C s 1,2}\left(\frac{d T}{d x} \cdot n_{x}+\frac{d T}{d y} \cdot n_{y}\right) \cdot \overrightarrow{\Delta \Gamma}=0
\end{gathered}
$$

Where $n_{x}$ and $n_{y}$ are the components of the normal vector $\vec{n}$ and $\overrightarrow{\Delta \Gamma}$ is the boundary vector. Heat flows between control volumes through control surfaces Cs (two for each sub-control volume). In numerical code, the energy equation is applied in the following manner for subcontrol volumes A, B, C and D:

- For sub-control volume A:

$$
Q_{A}=k_{A} \cdot\left(\frac{d T}{d x} \cdot \cos \theta_{2}+\frac{d T}{d y} \cdot \sin \theta_{2}\right) \cdot \overrightarrow{\Delta \Gamma}_{2}+k_{A} \cdot\left(\frac{d T}{d x} \cdot \cos \theta_{3}+\frac{d T}{d y} \cdot \sin \theta_{3}\right) \cdot \overrightarrow{\Delta \Gamma}_{3}
$$

- For sub-control volume B:

$$
Q_{B}=k_{B} \cdot\left(\frac{d T}{d x} \cdot \cos \theta_{3}+\frac{d T}{d y} \cdot \sin \theta_{3}\right) \cdot \overrightarrow{\Delta \Gamma}_{3}+k_{B} \cdot\left(\frac{d T}{d x} \cdot \cos \theta_{4}+\frac{d T}{d y} \cdot \sin \theta_{4}\right) \cdot \overrightarrow{\Delta \Gamma}_{4}
$$

- For sub-control volume C:

$$
Q_{C}=k_{C} \cdot\left(\frac{d T}{d x} \cdot \cos \theta_{4}+\frac{d T}{d y} \cdot \sin \theta_{4}\right) \cdot \overrightarrow{\Delta \Gamma}_{4}+k_{C} \cdot\left(\frac{d T}{d x} \cdot \cos \theta_{1}+\frac{d T}{d y} \cdot \sin \theta_{1}\right) \cdot \overrightarrow{\Delta \Gamma}_{1}
$$

- For sub-control volume D:

$$
Q_{D}=k_{D} \cdot\left(\frac{d T}{d x} \cdot \cos \theta_{1}+\frac{d T}{d y} \cdot \sin \theta_{1}\right) \cdot \overrightarrow{\Delta \Gamma}_{4}+k_{D} \cdot\left(\frac{d T}{d x} \cdot \cos \theta_{2}+\frac{d T}{d y} \cdot \sin \theta_{2}\right) \cdot \overrightarrow{\Delta \Gamma}_{2}
$$


Sum of fluxes to control volume equals to 0 :

$$
Q_{A}+Q_{B}+Q_{C}+Q_{D}=0
$$

Derivatives of temperature are obtained from the following equation:

$$
\begin{aligned}
& \frac{d T}{d x}=\frac{1}{|J|} \cdot\left(\frac{d T}{d \xi} \cdot \frac{d y}{d \eta}-\frac{d T}{d \eta} \cdot \frac{d y}{d \xi}\right) \\
& \frac{d T}{d y}=\frac{1}{|J|} \cdot\left(\frac{d T}{d \eta} \cdot \frac{d x}{d \xi}-\frac{d T}{d \xi} \cdot \frac{d x}{d \eta}\right)
\end{aligned}
$$

And the Jacobian of isoparimetric transformation is obtained according to the formula:

$$
|J|=\frac{d x}{d \xi} \cdot \frac{d y}{d \eta}-\frac{d y}{d \xi} \cdot \frac{d x}{d \eta}
$$

$T(\xi, \eta)$ is differentiated with respect to $\xi$ and $\eta$, and the values of $\frac{d T}{d \xi}$ and $\frac{d T}{d \eta}$ are computed in the middle of each control surface (see Tab. 3):

\begin{tabular}{|c|c|c|}
\hline Control Surface & $\boldsymbol{\xi}$ & $\boldsymbol{\eta}$ \\
\hline $\mathrm{Cs}_{1}$ & 0 & -0.5 \\
\hline $\mathrm{Cs}_{2}$ & 0.5 & 0 \\
\hline $\mathrm{Cs}_{3}$ & 0 & 0.5 \\
\hline $\mathrm{Cs}_{4}$ & -0.5 & 0 \\
\hline
\end{tabular}

Table 3. Values of isoparametric parameters $\xi, \eta$ for control surfaces

The system of heat balance equations (see eq. 19) is being solved for each control volume. Assuming the mixed type boundary conditions on the inner and the outer wall of tube, the temperature distribution inside the elliptical tube is obtained. The sample results for the tube from the $1^{\text {st }}$ row are presented on the Fig. 24 and Fig 25. Applied boundary conditions on the inner wall of the tube are: $h_{w a t}=5000 \mathrm{~W} /\left(\mathrm{m}^{2} \mathrm{~K}\right), T_{\text {wat-bulk }}=120{ }^{\circ} \mathrm{C}$. On the outer wall, $h_{c g}$ and $T_{c g-b u l k}$ - obtained for $t_{s}=0 \mathrm{~mm}$ and adequately $t_{s}=1 \mathrm{~mm}$ is assumed compare with Fig. 11.

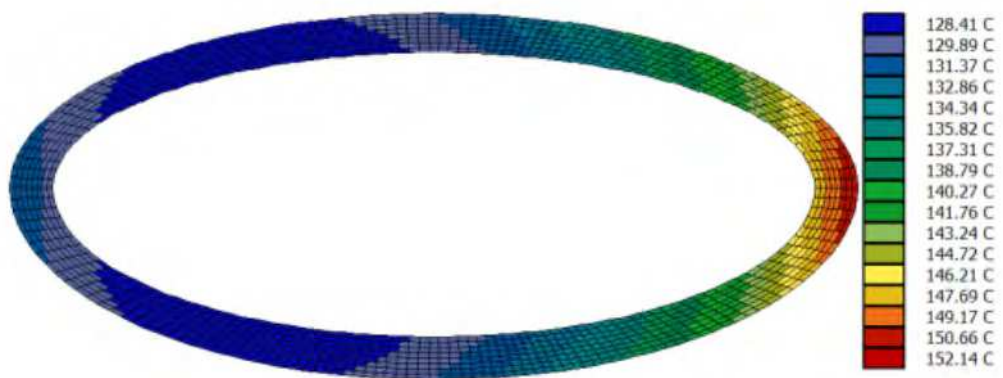

Fig. 24. Temperature distribution for $h_{\text {wat }}=5000 \mathrm{~W} /\left(\mathrm{m}^{2} \mathrm{~K}\right), T_{\text {wat-bulk }}=120^{\circ} \mathrm{C}, t_{s}=0 \mathrm{~mm}$ 


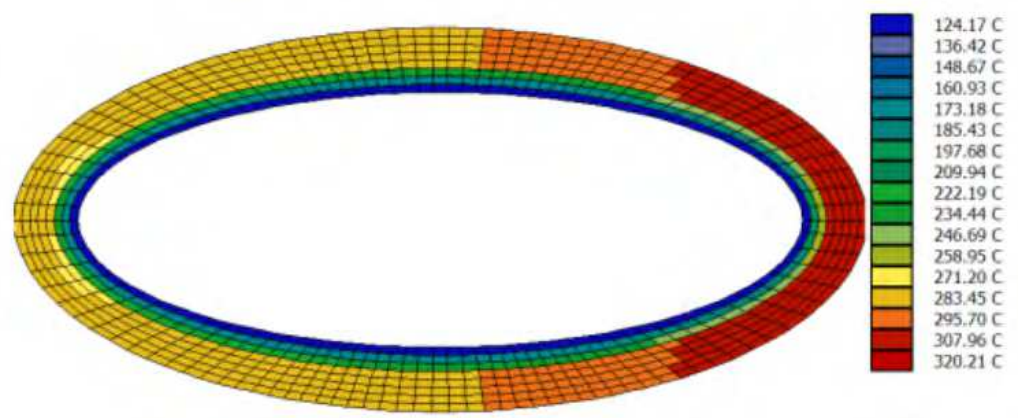

Fig. 25. Temperature distribution for $h_{\text {wat }}=5000 \mathrm{~W} /\left(\mathrm{m}^{2} \mathrm{~K}\right), T_{\text {wat-bulk }}=120^{\circ} \mathrm{C}, t_{s}=1 \mathrm{~mm}$

It is possible to observe, on Fig. 25, that when boiler scale exists inside the tube, e.g. Fig. 26, temperature increases significantly.

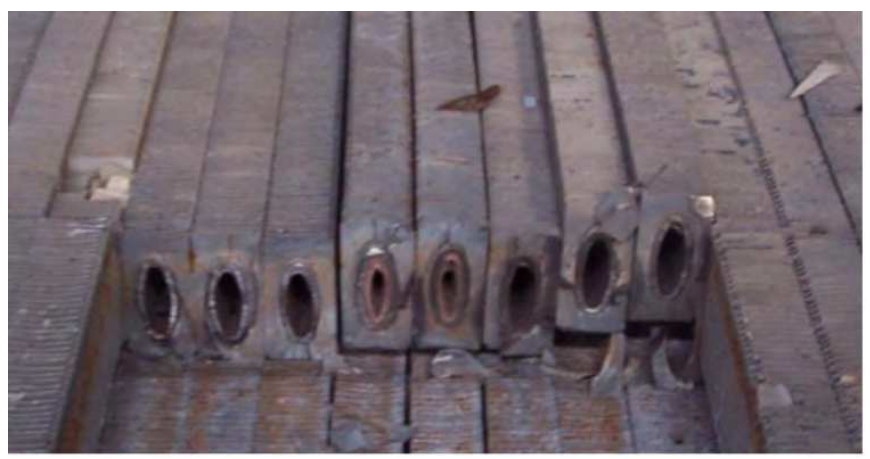

Fig. 26. Boiler scale observed in tubes of heat exchanger

The large increase of temperature brings about considerable thermal stresses inside all the tubes that may lead to fracture of the tube; see Fig. 1 \& Fig. 2.

\section{Analysis of stress state inside construction of high performance heat exchanger}

As mentioned before, structural analysis is carried out on basis of the Finite Element Method using the commercial code ANSYS. The manner in which the construction is supported is illustrated on Fig. 27. As it can be observed, the heat exchanger consists of two collectors with perforated bottoms to which all the tubes are welded. A shell connects the collectors and flat bars welded to the shell stiffen its structure. The frame increases the stiffness of the perforated bottom.

The other components of construction (a conffuser and a diffuser), not shown on Fig. 27 are welded to the shell. These parts constrain structure movement in the $y$ direction. The heat exchanger is also clamped at the distance $z=525 \mathrm{~mm}$ from the upper perforated bottom. The isoparametric linear shell element, SHELL 181 (ANSYS, 2009), used for the structural analysis is presented on Fig. 28. The CAD model of the heat exchanger is divided into a set 
of finite elements. Each part of the construction consists of elements with different thickness, $t_{\text {shell }}$ (see Tab. 4). Thickness of heat exchanger components are listed on Table 4.

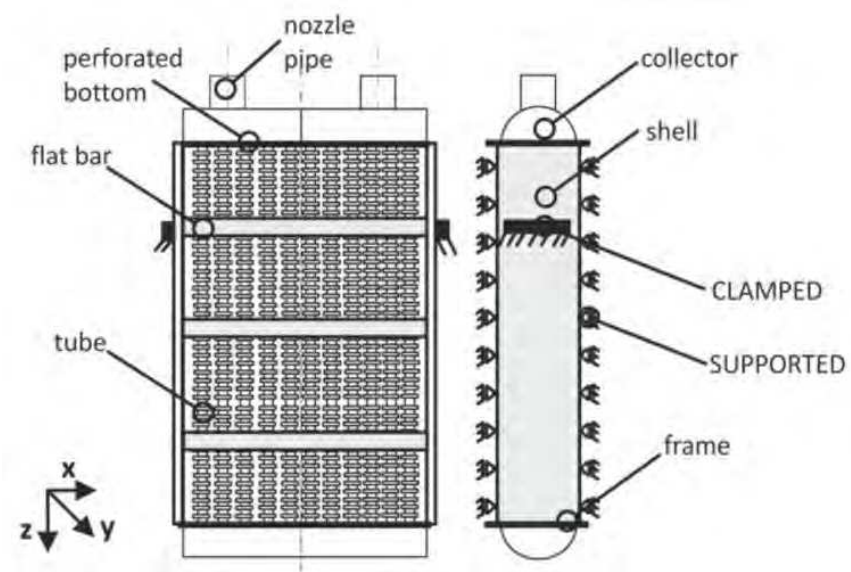

Fig. 27. Construction and support conditions for heat exchanger

\begin{tabular}{|c|c|}
\hline Component & $\boldsymbol{t}_{\text {shell }}[\mathrm{mm}]$ \\
\hline tube & 2 \\
\hline flat bar & 15 \\
\hline perforated bottom & 12 \\
\hline nozzle pipe & 2.5 \\
\hline frame & 20 \\
\hline collector & 6 \\
\hline shell & 8 \\
\hline
\end{tabular}

Table 4. Thickness of heat exchanger components

The midsurface is geometrical representation of the element. The maximal stress value is computed at the outer fibbers of the element.

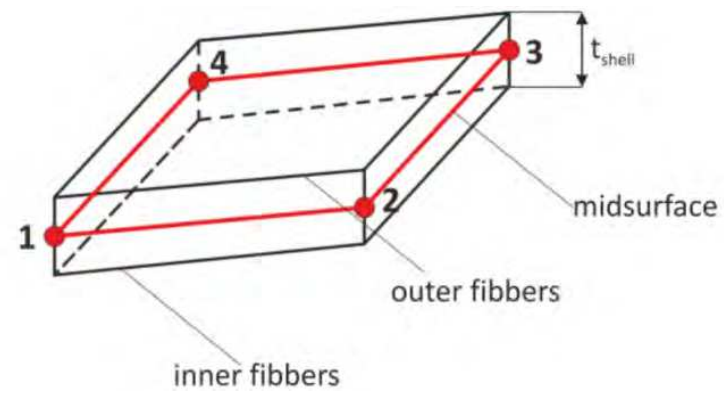

Fig. 28. Isoparametric shell element for structural calculations 
The set of equation being solved in structural analysis (ANSYS, 2009) is presented below:

$$
\left\lfloor K_{e}\right\rfloor \cdot\{u\}-\left\{F_{e}^{t h}\right\}=\left[M_{e}\right] \cdot\{\ddot{u}\}+\left\{F_{e}^{p r}\right\},
$$

where the element stiffness matrix $\left\lfloor K_{e}\right\rfloor$ is obtained from the following formula:

$$
\left\lfloor K_{e}\right\rfloor=\int_{V}[B]^{T} \cdot[D] \cdot[B] d V,
$$

where $[B]$ is the strain displacement matrix based on the element shape functions, $\{u\}$ is the nodal displacement vector and $[D]$ is the elasticity matrix. The thermal load vector is calculated on the basis of the equation:

$$
\left\lfloor F_{e}^{t h}\right\rfloor=\int_{V}[B]^{T} \cdot[D] \cdot\left\{\varepsilon_{t h}\right\} d V,
$$

The thermal strain vector $\left\{\varepsilon_{t h}\right\}$ is calculated on the basis of the following dependence:

$$
\left\{\varepsilon_{e}^{t h}\right\}=\alpha \cdot\left(T-T_{\text {ref }}\right),
$$

where $\alpha$ is the thermal expansion coefficient. Nodal temperatures $T$ are obtained from the thermal calculations, section 3. $T_{r e f}$ is the reference temperature assumed as $22^{\circ} \mathrm{C}$.

The element mass matrix $\left[M_{e}\right]$ is calculated on the basis of the following equation:

$$
\left\lfloor M_{e}\right\rfloor=\rho \cdot \int_{V}[N]^{T} \cdot[N] \cdot[D] d V,
$$

where $[N]$ is the element shape function matrix and $\rho$ is material density that the element consists of. For the computation steel $\mathrm{P} 355 \mathrm{NH}$ is used. Yield strength $Y_{S}$ of this material equals $355 \mathrm{MPa}$ and the density $\rho=7850 \mathrm{~kg} / \mathrm{m}^{3}$. The element pressure vector $\left\{F_{e}^{p r}\right\}$ is calculated according to the formula:

$$
\left\{F_{e}^{p r}\right\}=\int_{A}\left[N_{n}\right]^{T} \cdot\{P\} d A,
$$

where $\left[N_{n}\right]$ is the matrix of shape functions for normal motions at the surface and $\{P\}$ is the nodal pressure vector assumed equal to $p_{o p}-$ Tab. 2 .

The material properties used in the structural analysis are presented in Tab. 5.

\begin{tabular}{|c|c|c|}
\hline Name & Symbol & Value \\
\hline Young's modulus & $E[\mathrm{MPa}]$ & $2.1 \cdot 10^{5}$ \\
\hline Tangent modulus & $T[\mathrm{MPa}]$ & 470 \\
\hline Thermal expansion coeff. & $\alpha[1 / \mathrm{K}]$ & $1 \cdot 10^{-5}$ \\
\hline Poisson's ratio & $v$ & 0.3 \\
\hline
\end{tabular}

Table 5. Material properties of P355NH steel

\subsection{Analysis of stress state for construction of high performance heat exchanger with traditional collectors}

Results of numerical computation for nodal displacements, compressible stresses and equivalent stress acc. to von Misses are presented in this subchapter. Computations are carried out using the model of bilinear isotropic hardening (ANSYS, 2009; Chakrabarty, 2006), because computations in elastic range show that the allowable stresses inside the construction are exceeded. 
Thermal loadings for all the tubes are obtained using a program described in section 3 (computational case with $t_{s}=0 \mathrm{~mm}$ ). Because combustion gas flow is on the outer surface of the elliptical tubes, where heat flux density is the highest - avg. $80000 \mathrm{~W} / \mathrm{m}^{2}$. Heat flux density on the outer wall of perforated bottoms, collectors and nozzle pipes is low - avg. $5000 \mathrm{~W} / \mathrm{m}^{2}$. Therefore, temperature of walls for these parts is assumed to be equal to near wall temperature of liquid obtained from the flow distribution analysis - subsection 2.2. Thermal loading of construction is presented on Fig. 29. The contour map of nodal displacements $\{u\}$ is presented on Fig. 30 .

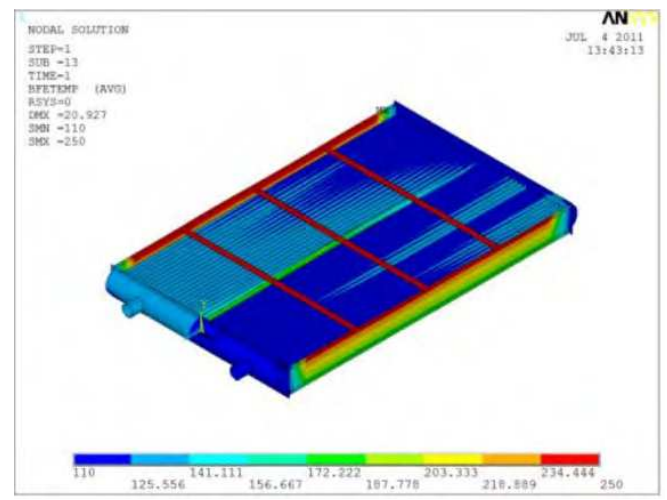

Fig. 29. Thermal loading for construction of high performance heat exchanger - traditional collector

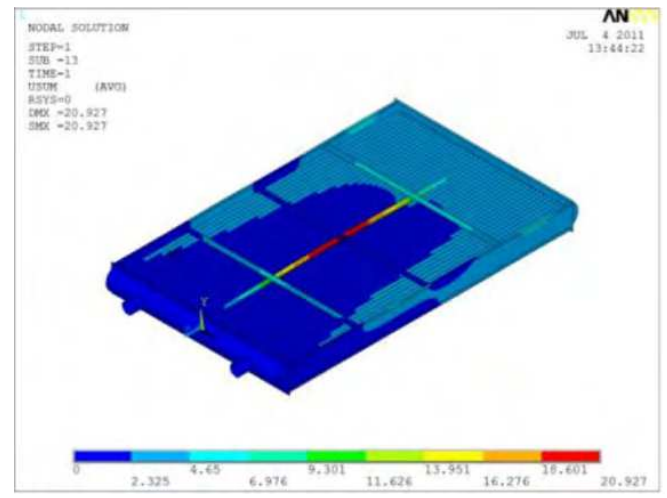

Fig. 30. Nodal displacement - high performance heat exchanger with traditional collectors

Displacements of the elliptical tube, that is the nearest to the axis of symmetry of the high performance heat exchanger are the largest at all. Comparing the results presented on Fig. 30 to Fig. 2, it is evident that reasons for the heat exchanger to break down are improper heat transfer conditions inside the construction. In the tube that broke down the temperature was significantly higher than in the others.

The next two figures - Fig. 31 \& Fig. 32 present the contour of equivalent stress distribution $\sigma_{e}$ acc. to von Mises (Bower, 2009), and the map of compressible stresses $\sigma_{3}$ inside the construction. The von Mises stress is calculated according to the formula: 


$$
\sigma_{e}=\frac{1}{2} \cdot \sqrt{\left(\sigma_{1}-\sigma_{2}\right)^{2}+\left(\sigma_{2}-\sigma_{3}\right)^{2}++\left(\sigma_{3}-\sigma_{1}\right)^{2}},
$$

where $\sigma_{1}, \sigma_{2}$ and $\sigma_{3}$ are principal stresses. It is possible to observe that in the shell and in the tube that was broken the stress level is the largest. According to the adopted plasticity model, maximum compressible stress in the broken tube equals to $205 \mathrm{MPa}$.

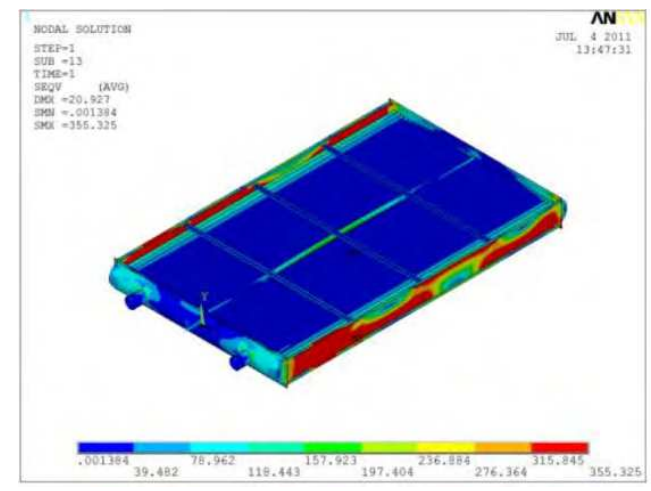

Fig. 31. Equivalent stress acc. to von Mises - heat exchanger with traditional collector

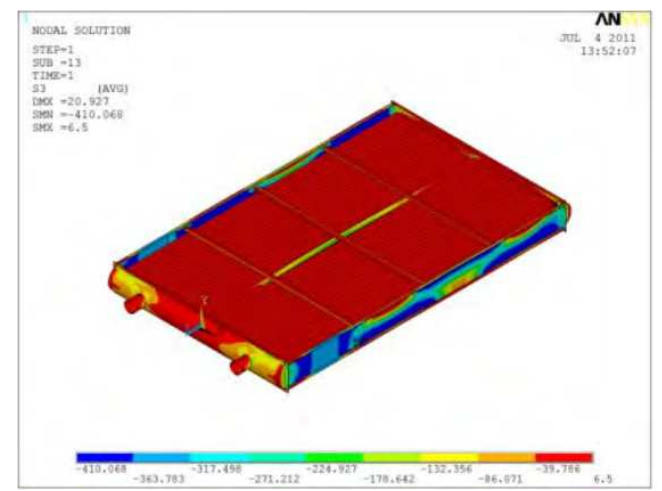

Fig. 32. Compressible stresses - heat exchanger with traditional collector

Because the tube is slender and thin, it is prone to buckling, that is caused by compressible loads. Buckling computations (Brush \& Almroth, 1975) are carried out in order to understand the manner how the tube was destroyed. The assumed model of buckling is presented on Fig 33. The left end is clamped as opposed to the right one that is supported in vertical direction.

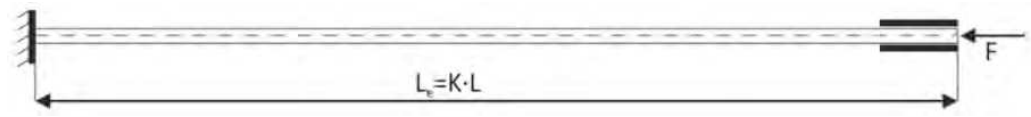

Fig. 33. Buckling model of elliptical tube 
The effective length of the tube equals:

$$
L_{e}=K \cdot L,
$$

where $K$ equals to the tube effective length factor and $L$ is the unsupported length of the tube.

The slenderness ratio $s$ for the tube presented on Fig. 33 equals:

$$
s=\frac{L_{e}}{\sqrt{\frac{\operatorname{Imin}}{A}}}
$$

where $I_{\min }$ equals to minimal area moment of inertia for the tube cross section and $A$ equals to the cross - sectional area of the tube. The critical slenderness ratio $s_{c r}$ is calculated according to the formula:

$$
S_{c r}=\pi \cdot \sqrt{\frac{E}{Y_{s}}}
$$

The following values, Tab. 6, are used in calculations:

\begin{tabular}{|c|c|c|}
\hline Name & Symbol & Value \\
\hline Tube effective length factor & $K$ & 0.5 \\
\hline Length of unsupported tube & $L[\mathrm{~m}]$ & 2.1 \\
\hline Minimal area moment of inertia & $I_{\min }\left[\mathrm{m}^{4}\right]$ & $4.85 \cdot 10^{-9}$ \\
\hline Cross - sectional area of tube & $A\left[\mathrm{~m}^{2}\right]$ & $1.7 \cdot 10^{-4}$ \\
\hline Poisson's ratio & $v$ & 0.3 \\
\hline Critical slenderness ratio & $s_{c r}$ & 73.1 \\
\hline Slenderness ratio & $s$ & 168 \\
\hline
\end{tabular}

Table 6. Parameters taken into buckling calculations

Since $s$ is larger than $s_{c r}$, see Tab.6, buckling occurs in the elastic range. The following formula allows calculating the critical compressible stress:

$$
\sigma_{\text {crit }}=\frac{\pi^{2} \cdot E}{s^{2}}
$$

The allowable stresses obtained on the basis of procedure $(28-32)$ are less than $\sigma_{\text {crit }}=66$ $\mathrm{MPa}$. Comparing $\sigma_{\text {crit }}$ to the maximal value from the contour map of compressible stresses in the construction, it is evident, that the critical stress is exceeded in the tube nearest to the axis of symmetry. This explains the manner of tube deformation, after the damage, compare with Fig 2.

\subsection{Analysis of stress state for construction of high performance heat exchanger with modified collectors}

For the construction of the high performance heat exchanger, computations are carried out in the elastic range, because the $\sigma_{e}$ for this computations is lower than $Y_{s}$. On Fig. $34 \&$ Fig. 35 thermal loading and the nodal displacements of construction are presented. 


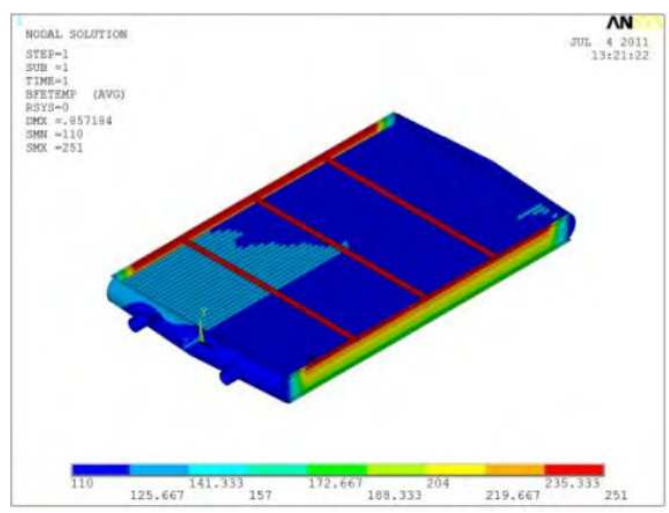

Fig. 34. Thermal loading for construction of high performance heat exchanger - modified collectors

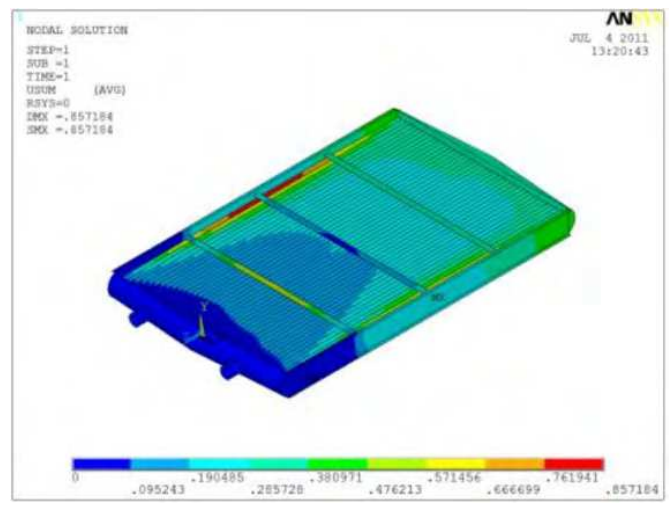

Fig. 35. Nodal displacement - high performance heat exchanger with modified collectors

It is possible to observe that, for the proposed construction of the collector, displacements are significantly lower than for the typical one. The maximum displacement is over 20 times lower - compare Fig. 35 and Fig. 30.

For the modified construction, distribution of equivalent stress acc. to von Mises is presented on Fig. 36. The $\sigma_{e}$ value obtained from computations does not exceed $Y_{S}$, therefore the construction is safe to use. Moreover the compressible stresses $\sigma_{3}$ in the tubes, Fig. 37, do not exceed $22 \mathrm{MPa}$ and are significantly lower than $\sigma_{\text {crit }}$.

The modified construction of the collectors improves flow distribution inside the tubes through the heat exchanger. Consequently, thermal load acting on the tubes is lower than in the case of the traditional construction of the collectors. Comparing the maps of nodal displacements $\{u\}$, effective stresses $\sigma_{e}$ according to von Mises and compressible stresses $\sigma_{3}$ for the traditional and the modified construction of the collectors, it is evident that the proposed construction carries thermal loads better than the one actually available in manufacturing. 


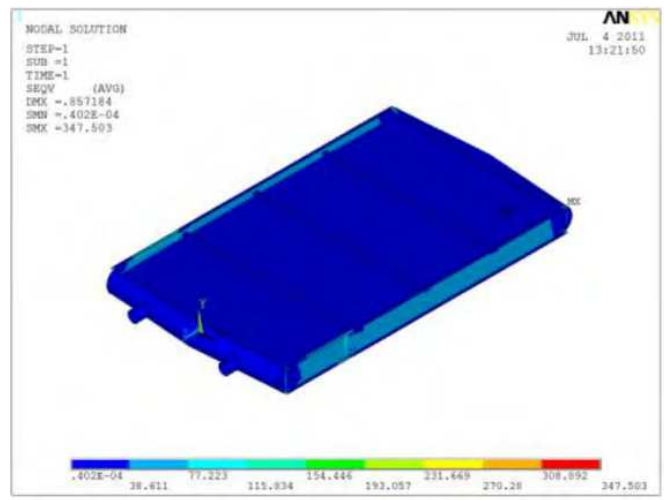

Fig. 36. Equivalent stress acc. to von Mises - heat exchanger with modified collector

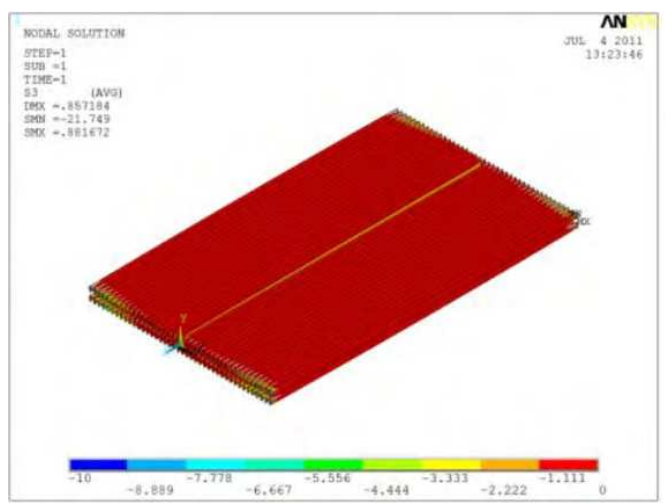

Fig. 37. Compressible stresses - heat exchanger with modified collector

\section{Conclusions}

Improper liquid distribution in the tubes of the presented heat exchanger causes the mass flow rates of medium flowing inside all the tubes being far from uniform. This implicates that heat transfer conditions inside the tubes differ significantly. Consequently, the temperatures as well as the thermal stresses inside all the tubes are different, often exceeding the allowable stress limits.

Reasons of high performance heat exchanger failure, on the basis of the real model applied in the industry, were investigated. The zones and the locations where the allowable stresses are exceeded were presented in the paper. Presented analysis may be applied not only in analysing the stress state in the high performance heat exchanger, but also in accessing safety of boilers, pressure vessels, shell and tube heat exchangers and many other devices applied in the thermal power engineering.

Furthermore, the new and easy in manufacturing model of collectors is presented. On the basis of numerical computation it was proven that application of the new collectors ensures 
proper flow distribution inside all the tubes that consequently reduces significantly thermal stresses inside the construction.

With continuous increase in computational power it will be possible to investigate in more detail the flow behaviour and heat transfer conditions inside the high performance heat exchanger, including e.g. the phase change effect. If liquid evaporates, the heat transfer coefficient increases significantly and due to the local pressure drop, the cavitation may occur inside the tube that leads to erosion of the tube wall. Consequently, material of the tube is damaged and less resistible on acting stresses. Therefore, the real values of $\sigma_{\mathrm{e}}$ and $\sigma_{3}$ may be larger than the presented in the paper. This effect should be encountered into calculations in the future.

Wall temperature increases significantly in the tubes where the mass flow rates are low. If water is not prepared properly, boiler scale formation is more intensive than in the other tubes. Influence of boiler scale thickness and its thermal conductivity on the stress state in the high performance heat exchanger should be investigated in the future.

\section{References}

Anderson, J. D. (1995). Computational Fluid Dynamics: The Basics with Applications $6^{\text {th }}$ Ed., McGraw Hill, ISBN: 0070016852

ANSYS, (2008). CFX - Solver Theory Guide, http://www1.ansys.com/customer/content/documentation/120/cfx/xthry.pdf, USA

ANSYS, (2009). Theory Reference for the Mechanical ADPL and Mechanical Applications, http://www1.ansys.com/customer/content/documentation/121/ans_thry.pdf

Bansat, B.; Mtiller-Steinhagen, H. (1993). Crystallization fouling in plate heat exchangers., ASME Journal of Heat Transfer, pp. 584-591, ISSN 0022 -1481, Vol. 115, No 3

Bird, R. B. (2001). Transport Phenomena $2^{\text {nd }}$ Edition, Wiley, ISBN-10: 0471410772, ISBN-13: 9780471410775

Bordallo, S. N. \& Saboya, F. E. M. (1999). Pressure Drop Coefficients for Elliptic and Circular Sections in One, Two and Three-Row Arrangements of Plate Fin and Tube Heat Exchangers, Journal of the Brazilian Society of Mechanical Sciences, Vol. 21, No. 4, ISSN 0100-7386

Bower, A. F. (2009). Applied Mechanics of Solids, CRC Press, ISBN-10: 9781439802472, ISBN-13: 978-1439802472

Brush, D. O \& Almroth, B. O. (1975). Buckling of bars, plates, and shells, McGraw Hill, ISBN-10: 0070085935, ISBN-13: 978-0070085930

Chakrabarty, J. (2006). Theory of Plasticity, Butterworth Heinemann, ISBN-10: 0-7506-6638-2, ISBN-13: 978-0-7506-6638-1

Chung, T.J. (2010): Computational Fluid Dynamics $2^{\text {nd }}$ Ed., Cambridge University Press, ISBN10: 0521769698, ISBN-13: 978-0521769693

Egorov, Y. \& Menter F. (2008). Development and Application of SST-SAS Turbulence Model in the DESIDER Project, Notes on Numerical Fluid Mechanics and Multidisciplinary Design, pp. 261 - 270, Vol. 97

Ferziger, J. H \& Peric, M. (1999). Computational Methods for Fluid Dynamics $2^{\text {nd }}$ Ed., Springer, ISBN: 3540653732

Freeborn, J. \& Lewis, D. (1962). Initiation of boiler scale formation, Journal of Mechanical Engineering Sciences, pp. 46 - 52, Vol. 4 
Gnielinski, V. (1976). New equations for heat and mass transfer in turbulent pipe and channel flow, International Journal of Chemical Engineering, pp. 359-367, Vol. 16, No. 1

Gresho, P. M. \& Sani, R. L. (2000). Incompressible Flow and the Finite Element Method, Willey, ISBN: 0471492493

Hutton, D. V. (2003). Fundamentals of Finite Element Analysis, McGraw Hill, ISBN - 10 0072922362, ISBN - 13 978-0072922363

Ibrahim, T. A. \& Gomaa, A. (2009). Thermal performance criteria of elliptic tube bundle in crossflow, International Journal of Thermal Sciences, pp. 2148-2158, Vol. 48, No. 11

Idem, S.; Jacobi, A. M. \& Goldchmidt, V. W. (1990). Heat Transfer Characterization of a FinnedTube Heat Exchanger (with and without Condensation). Transaction of the ASME, pp. 64-70, Vol. 112

Incopera, F. P \& De Witt, D. P. (2001). Fundamentals of Heat and Mass Transfer $5^{\text {th }}$ Ed., Willey, ISBN-10: 0471386502, ISBN-13: 978-0471386506

Jang, J. Y.; Yang, J. Y. (1998). Experimental and Numerical Analysis of the Thermal-Hydraulic Characteristics of Elliptic Finned-Tube Heat Exchangers, Heat Transfer Engineering, pp. 55-67, Vol.19, No. 4

Khan, M.G.; Fartaj, A. \& Ting, D. S. K. (2004). An experimental characterization of cross-flow cooling of air via an in-line elliptical tube array, International Journal of Heat and Fluid Flow, pp. 636-648, Vol. 25, No. 4

Lewis, R. W.; Nithiarasu, P. \& Seetharamu, K. N. (2004). Fundamentals of the finite element method for heat and fluid flow, Willey, ISBN-10: 0470847891, ISBN-13: 9780470847893341

Li, B.; Feng, B.; He. Y.L. \& Tao W.Q. (2006). Experimental study on friction factor and numerical simulation on flow and heat transfer in an alternating elliptical axis tube, Applied Thermal Engineering, pp. 2336-2344, Vol. 26, Issue 17-18

Logan, D.L. (2011). A First Course in the Finite Element Method $5^{\text {th }}$ Ed., CL-Engineering, ISBN10 0495668257, ISBN-13 978-0495668251

Łopata, S. \& Ocłon, P. (2010) Coupled thermal - structural analysis of the high performance heat exchanger with finned elliptical (in polish), Systems, Technologies and Energetic Devices, Collective Work edited by J. Taler, Cracow University of Technology press, pp. $826-840$, Cracow

Łopata, S. \& Ocłon, P. (2010). Investigation of the flow conditions in a high-performance heat exchanger, Archives of Thermodynamics; pp. 37-50, Vol. 31, no. 3, Gdańsk

Łopata, S. \& Ocłoń, P. (2011). The Stress State analysis of the high performance heat exchanger, Technical Transactions; Cracow University of Technology press, pp. 360-368, Issue 7, Year 108, Cracow

Matos, R. S.; Vargas, J. V. C.; Laursen, T. A. \& Bejan, A. (2004). Optimally staggered finned circular and elliptic tubes in forced convection, International Journal of Heat and Mass Transfer, pp. 1347-1359, Vol.47, No. 6-7

Nagatha, H. (2004). The Development of Heat Exchanger with Elliptic Tubes for High Viscous Liquid: Mitsui Zosen Technical Review, pp. 29-33 ISSN: 0026-6825, No. 183, Japan

Najibi, S. H; Miiller-Steinhagen, H. \& Jamialahmadi, M. (1997). Calcium sulphate scale formation during subcooled flow boiling, Chemical Engineering Science, pp. 1265 1284, Vol 52, No. 8, Great Britan 
Nebot, E.; Casanueva, J. F.; Casanueva, T. \& Sales, D. (2007). Model for fouling deposition on power plant steam condensers cooled with seawater: Effect of water velocity and tube material, International Journal of Heat and Mass Transfer, pp. 3351-3358, Vol. 50

Nishiyama, H.; Ota, T. \& Matsumo, T. (1988). Heat Transfer and Flow around an Elliptic Cylinders in Tandem Arrangement, JSME International Journal Series II, ISSN 09148817 , pp. $410-419$, vol. 31

Ocłon, P. \& Łopata, S. (2011). Modelling of the flow distribution inside the collectors of the high performance heat exchanger, Technical Transactions Mechanics 4-M/2011/B, pp. 393 - 400, Cracow University of Technology press, , Cracow

Quan, Z., Chen, Y. \& Chongfang, M. A. (1997). Experimental Study of Fouling on Heat Transfer Surface During Forced Convective Heat Transfer, Chinese Journal of Chemical Engineering, pp. 535 - 540, Vol. 16, No. 4

Reddy, J. N. (1993). Introduction to Finite Element Method, McGraw Hill, ISBN10: 0070513554, ISBN- 13: 978-0070513556

Rocha, L. A. O.; Saboya, F. E. M. \& Vargas, J.V.C. (1997). A comparative study of elliptical and circular sections in one- and two-row tubes and plate fin heat exchangers, International Journal of Heat and Fluid Flow, pp. 247-252, Vol. 18, Issue 2

Saboya, F. E. M. \& Sparrow, E. M. (1974). Local and Average Transfer Coefficients for One-Row Plate Fin and Tube Heat Exchanger Configurations, Journal of Heat Transfer, pp. 265272, Vol. 96

Saboya, S. M. \& Saboya, F. E. M. (1981). Transfer Coefficients for Plate Fin and Elliptical Tube Heat Exchangers, Proceedings of the VI Brazilian Congress of Mechanical Engineering, pp. 153-162

Smith, I. M \& Griffiths, D. V. (2004). Programming the Finite Element Method, Willey, ISBN-10 047084969X, ISBN-13 978- 0470849699

Taler, D. (2009). Dynamics of Tube Heat Exchangers, Monograph 193, AGH University of Science and Technology Press, ISSN 0867-6631, Cracow, Poland (in Polish)

Taler, J. \& Duda, P. (2006). Solving Direct and Inverse Heat Conduction Problems, Springer, ISBN 978-3-540-33470-5

White F. (2003). Fluid Mechanics, McGraw Hill, ISBN - 10 0071215662, ISBN - 13 9780071215664

Zienkiewicz, O. C. \& Taylor, R. L. (2000). The Finite Element Method 5th Ed., Elsevier, Vol.1-3, ISBN 978-0-7506-5055-7 


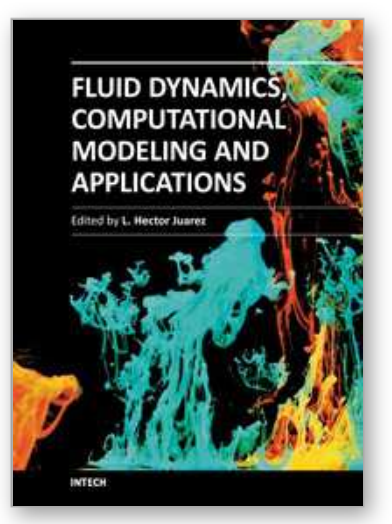

\author{
Fluid Dynamics, Computational Modeling and Applications \\ Edited by Dr. L. Hector Juarez
}

ISBN 978-953-51-0052-2

Hard cover, 660 pages

Publisher InTech

Published online 24, February, 2012

Published in print edition February, 2012

The content of this book covers several up-to-date topics in fluid dynamics, computational modeling and its applications, and it is intended to serve as a general reference for scientists, engineers, and graduate students. The book is comprised of 30 chapters divided into 5 parts, which include: winds, building and risk prevention; multiphase flow, structures and gases; heat transfer, combustion and energy; medical and biomechanical applications; and other important themes. This book also provides a comprehensive overview of computational fluid dynamics and applications, without excluding experimental and theoretical aspects.

\title{
How to reference
}

In order to correctly reference this scholarly work, feel free to copy and paste the following:

Stanisław Łopata and Paweł Ocłoń (2012). Modelling and Optimizing Operating Conditions of Heat Exchanger with Finned Elliptical Tubes, Fluid Dynamics, Computational Modeling and Applications, Dr. L. Hector Juarez (Ed.), ISBN: 978-953-51-0052-2, InTech, Available from: http://www.intechopen.com/books/fluid-dynamicscomputational-modeling-and-applications/modelling-and-optimizing-operating-conditions-of-heat-exchangerwith-finned-elliptical-tubes

\section{INTECH}

open science | open minds

\section{InTech Europe}

University Campus STeP Ri Slavka Krautzeka 83/A 51000 Rijeka, Croatia Phone: +385 (51) 770447 Fax: +385 (51) 686166 www.intechopen.com

\section{InTech China}

Unit 405, Office Block, Hotel Equatorial Shanghai No.65, Yan An Road (West), Shanghai, 200040, China 中国上海市延安西路65号上海国际贵都大饭店办公楼405单元 Phone: +86-21-62489820

Fax: +86-21-62489821 
(C) 2012 The Author(s). Licensee IntechOpen. This is an open access article distributed under the terms of the Creative Commons Attribution 3.0 License, which permits unrestricted use, distribution, and reproduction in any medium, provided the original work is properly cited. 